\title{
Ozone profiles above Kiruna from two ground-based radiometers
}

\author{
Niall J. Ryan ${ }^{1}$, Kaley A. Walker ${ }^{1}$, Uwe Raffalski ${ }^{2}$, Rigel Kivi ${ }^{3}$, Jochen Gross ${ }^{4}$, and Gloria L. Manney ${ }^{5,6}$ \\ ${ }^{1}$ Department of Physics, University of Toronto, 60 St. George Street, Toronto, Ontario, M5S 1A7, Canada \\ ${ }^{2}$ Swedish Institute of Space Physics, Box 812, 98128 Kiruna, Sweden \\ ${ }^{3}$ Finnish Meteorological Institute, Arctic Research Centre, Tähteläntie 62, 99600 Sodankylä, Finland \\ ${ }^{4}$ Karlsruhe Institute of Technology, P.O. Box 3640, 76021 Karlsruhe, Germany \\ ${ }^{5}$ NorthWest Research Associates, Socorro, New Mexico, USA \\ ${ }^{6}$ Department of Physics, New Mexico Institute of Mining and Technology, Socorro, New Mexico 87801, USA
}

Correspondence to: Kaley A. Walker (kaley.walker@utoronto.ca)

Received: 13 March 2016 - Published in Atmos. Meas. Tech. Discuss.: 14 April 2016

Revised: 19 July 2016 - Accepted: 3 August 2016 - Published: 12 September 2016

\begin{abstract}
This paper presents new atmospheric ozone concentration profiles retrieved from measurements made with two ground-based millimetre-wave radiometers in Kiruna, Sweden. The instruments are the Kiruna Microwave Radiometer (KIMRA) and the Millimeter wave Radiometer 2 (MIRA 2). The ozone concentration profiles are retrieved using an optimal estimation inversion technique, and they cover an altitude range of $\sim 16-54 \mathrm{~km}$, with an altitude resolution of, at best, $8 \mathrm{~km}$. The KIMRA and MIRA 2 measurements are compared to each other, to measurements from balloon-borne ozonesonde measurements at Sodankylä, Finland, and to measurements made by the Microwave Limb Sounder (MLS) aboard the Aura satellite. KIMRA has a correlation of 0.82 , but shows a low bias, with respect to the ozonesonde data, and MIRA 2 shows a smaller magnitude low bias and a 0.98 correlation coefficient. Both radiometers are in general agreement with each other and with MLS data, showing high correlation coefficients, but there are differences between measurements that are not explained by random errors. An oscillatory bias with a peak of approximately \pm 1 ppmv is identified in the KIMRA ozone profiles over an altitude range of $\sim 18-35 \mathrm{~km}$, and is believed to be due to baseline wave features that are present in the spectra. A time series analysis of KIMRA ozone for winters 20082013 shows the existence of a local wintertime minimum in the ozone profile above Kiruna. The measurements have been ongoing at Kiruna since 2002 and late 2012 for KIMRA and MIRA 2, respectively.
\end{abstract}

\section{Introduction}

Total column ozone $\left(\mathrm{O}_{3}\right)$ has decreased by approximately $2.5 \%$ over most of the planet during the 1980s and 1990s due to increased emissions of chlorofluorocarbons (CFCs) (WMO, 2014). Thanks to the Montreal Protocol, and the ban on CFC emissions, total ozone columns have remained relatively unchanged since then, with recent indications of recovery (UNEP, 2015). Models suggest that these concentrations will recover to pre-1980 values by approximately 2060 , but the projections are strongly dependant on future emissions of carbon dioxide $\left(\mathrm{CO}_{2}\right)$, nitrous oxide $\left(\mathrm{N}_{2} \mathrm{O}\right)$, and methane $\left(\mathrm{CH}_{4}\right)$ (WMO, 2014). Long-term (seasonal, yearly, and decadal) measurements of stratospheric $\mathrm{O}_{3}$ are an essential part of understanding how compositional changes in the atmosphere are linked to the future radiative balance of the planet. Measurements of the Arctic atmosphere are particularly important as the Arctic is known to respond relatively rapidly to compositional changes that affect the radiative budget of the planet (IPCC, 2013). With the decrease in observations from profiling satellite instruments, groundbased instruments will represent an increasingly important source of measurements needed to maintain a long-term stratospheric $\mathrm{O}_{3}$ profile record. Calibrations with respect to ground-based instruments are also needed in order to combine data from current and future satellites.

Millimetre-wave radiometry is a well-established technique for atmospheric remote sensing. The technique offers the advantage of measuring radiation emitted from the atmosphere, allowing year-round measurements at high lati- 
tudes as there is no reliance on the sun as a source. High frequency resolution in measured spectra, and the relatively low Doppler broadening compared to pressure broadening in the atmosphere, allows the retrieval of altitude profiles of atmospheric composition with ground-based instruments.

Millimetre-wave datasets of Arctic $\mathrm{O}_{3}$ are sparse in time and in location. The Ozone Radiometer for Atmospheric Measurements (OZORAM) (Palm et al., 2010) has operated in Ny Ålesund, Spitsbergen $\left(79^{\circ} \mathrm{N}, 12^{\circ} \mathrm{E}\right)$, since November 1994 and has been used for studies such as Palm et al. (2005) and Langer et al. (1999). The Radiometer for Atmospheric Measurements At Summit (RAMAS) operated in Summit, Greenland $\left(72^{\circ} \mathrm{N}, 38^{\circ} \mathrm{W}\right)$, briefly in 2003 (Golchert et al., 2005). The Kiruna Microwave Radiometer (KIMRA) has operated in Kiruna, Sweden, since 2002, and the $\mathrm{O}_{3}$ measurements have been used to investigate the 2002/2003 winter (Raffalski et al., 2005) and for validation of the satellite instruments: Global Ozone Monitoring by Occultation of Stars (GOMOS) (Meijer et al., 2004) and Michelson Interferometer for Passive Remote Sounding (MIPAS) (Steck et al., 2007) on board the Envisat satellite. The Millimeter wave Radiometer 2 (MIRA 2) has been housed at Kiruna on previous occasions and has been used to study the evolution of $\mathrm{O}_{3}$ during the SOLVE/THESEO 2000 campaign (Kopp et al., 2003). Between 2004 and 2010, MIRA 2 was stationed at Pico Espejo, Mérida, Venezuela (4800 m a.s.l.), and used for validation of the Sub-Millimetre Radiometer (SMR) aboard the Odin satellite (Kopp et al., 2007). MIRA 2 has been installed indefinitely in Kiruna since November 2012.

The aim of this work is to develop and deploy operational inversion schemes that use the atmospheric spectra provided by KIMRA and MIRA 2 to retrieve $\mathrm{O}_{3}$ concentrations above Kiruna, to assess the quality of these gas profiles through comparison with other $\mathrm{O}_{3}$ measurements, and to examine the KIMRA data through an assessment of the wintertime variability of $\mathrm{O}_{3}$ above Kiruna. The inversion set-up that was developed for this purpose can also be used for future measurements, as well as for older KIMRA data that have yet to be analysed.

Section 2 describes the instruments and datasets used in the study. Section 3 outlines the inversion set-ups used for KIMRA and MIRA 2. Section 4 shows the comparison of the retrieved $\mathrm{O}_{3}$ profiles from KIMRA and MIRA 2. In Sect. 5, the KIMRA and MIRA 2 profiles are compared to measurements from ozonesonde instruments launched from Sodankylä, and from the satellite-borne instrument, Microwave Limb Sounder (MLS), on Aura. Section 6 examines the KIMRA data by looking at the variability of wintertime $\mathrm{O}_{3}$ concentrations above Kiruna from 2008 to 2013, and Sect. 7 offers some concluding remarks.

\section{Ground-based instruments and datasets}

\subsection{KIMRA}

KIMRA was partly designed by the Institute for Meteorology and Climate Research (IMK) at the Karlsruhe Institute of Technology (KIT) (Raffalski et al., 2002) and built at the Swedish Institute of Space Physics (IRF) in Kiruna, Sweden. The instrument has been operated at IRF since 2002. KIMRA operates in the frequency range between 195 and $233 \mathrm{GHz}$. The instrument has the capability to measure many species by tuning within this frequency range but, due to baseline issues, has only been used to measure $\mathrm{O}_{3}$ and, since 2007, carbon monoxide (CO).

The detector in KIMRA is a Schottky diode mixer cooled to $\sim 25 \mathrm{~K}$ within a cryostat. It has a single sideband (SSB) noise temperature of $\sim 1800 \mathrm{~K}$. The sideband filter is a Martin-Pupplett interferometer. A path length modulator (PLM) lies in the beam path to suppress standing waves between optical elements, which contribute to waves in the baseline of the spectra, or baseline waves. There are two black bodies for calibration: at $\sim 125$ and $\sim 293 \mathrm{~K}$ for the cold and hot targets, respectively. The cold target is inside the cryostat. KIMRA has an acousto-optical spectrometer (AOS) with a practical bandwidth of $1.27 \mathrm{GHz}$ and 1801 channels giving a resolution of $\sim 0.7 \mathrm{MHz}$, as well as two Fast Fourier Transform Spectrometers (FFTSs). The narrowband FFTS, installed in 2007, is often centred on a nearby CO line and has been used in retrieving $\mathrm{CO}$ between 40 and $80 \mathrm{~km}$ (Hoffmann et al., 2011), and the broadband FFTS, installed in 2012, has been used to measure atmospheric spectra in the region of $230 \mathrm{GHz}$. The data from the AOS are presented here as its time series extends back to 2002 and the spectrometer is the same model as the MIRA 2 spectrometer. A periscope-like mirror system, with the sky mirror located in a dome on the roof of IRF, allows KIMRA to view in any direction on the sky. The elevation angle for each measurement is chosen automatically between 7 and $55^{\circ}$ to give the highest signal-to-noise ratio (SNR) according to the tropospheric transmissivity. $\mathrm{O}_{3}$ measurement durations range from $15 \mathrm{~min}$ to $360 \mathrm{~min}$, depending on the atmospheric conditions. First technical descriptions of the instrument are given in Raffalski et al. (2002).

The KIMRA dataset presented here spans the time from 2008 to 2013, with some gaps in operation. The data used for intercomparison of the retrieved $\mathrm{O}_{3}$ profiles are from 20 November 2012 to 31 May 2013, and consist of 1152 retrieved profiles. The data used in examining the wintertime $\mathrm{O}_{3}$ variability above Kiruna are from January to March over the years 2008, 2009, 2010, 2011, and 2013. Data from January-May 2012 were not available. While measurement data from IRF exist, with interruptions, as far back as 2002, the KIMRA data used here from winter/spring 2012/2013 were selected to overlap with MIRA 2. The January-March data for the other years were selected because $\mathrm{O}_{3}$ above 
Kiruna is expected to have the most variation over this time due to chemistry and dynamics: this makes it an interesting dataset to study.

KIMRA looks only directly north or south for all of these measurements. The elevation angle changes for each measurement, which prevents the averaging of spectra, so each measured spectrum is inverted and any averaging of the retrieved profiles can be applied afterwards. As a result, the signal-to-noise ratio (SNR) changes for each spectrum due to atmospheric conditions and the measurement duration. The system's local oscillator (LO) is adjusted frequently (often every other measurement) in KIMRA, which gives two differing spectral regions to be inverted. In one case, the LO is such that the $\mathrm{CO}$ line at $230.535 \mathrm{GHz}$ is in the spectrum (KIMRA_O ${ }_{3} \mathrm{CO}$ measurement). In the other case, the centre frequency is shifted up by $34 \mathrm{MHz}$. The spectrum for this case is centred on the $\mathrm{O}_{3}$ line and does not contain the $\mathrm{CO}$ line (KIMRA_O $\mathrm{O}_{3} \mathrm{O}_{3}$ measurement). The reason for changing the $\mathrm{LO}$ was to see if incorporating more of the $\mathrm{O}_{3}$ line in the spectrum would cause the inversion to improve/differ (however, this result is not tested here). Slightly different inversion set-ups were needed to account for these different cases.

\subsection{MIRA 2}

MIRA 2 was developed at the Forschungszentrum Karlsruhe to measure $\mathrm{O}_{3}, \mathrm{ClO}, \mathrm{HNO}_{3}$, and $\mathrm{N}_{2} \mathrm{O}$ between 268 and $280 \mathrm{GHz}$ (Berg et al., 1998). The detector is a Schottky diode mixer cooled to $\sim 25 \mathrm{~K}$ within a cryostat. The SSB noise temperature is $\sim 800 \mathrm{~K}$. The cold and hot targets are at $\sim 47$ and $\sim 300 \mathrm{~K}$ respectively. The cold target is located inside the cryostat. The sideband filter is a Martin-Pupplett interferometer. The sky mirror is contained within a removable periscope, which sticks out through a north-facing window. The MIRA 2 AOS has a bandwidth of $1.4 \mathrm{GHz}$, and 2048 channels giving a resolution of approximately $0.7 \mathrm{MHz}$. The spectra are centred on the $\mathrm{O}_{3}$ line at $273.051 \mathrm{GHz}$. A PLM lies in the beam path to reduce the effect of standing waves. A more detailed description of the instrument can be found in Berg et al. (1998).

The dataset from MIRA 2 presented here spans 1 December 2012 to 25 April 2013, and consists of 979 retrieved profiles. Inversions of measurements from May were not included because of instrumental problems. MIRA 2 continuously points north for all of the measurements presented here. As with KIMRA, the elevation angle of each measurement is automatically chosen to give the best SNR according to the atmospheric conditions.

\section{Inversion inputs and characteristics}

\subsection{Forward and inverse model parameters}

The forward model used for these inversions is the second release of the Atmospheric Radiative Transfer Simulator: ARTS 2 (Eriksson et al., 2011). The inversion is done using the package Qpack 2 (Eriksson et al., 2005), which uses the optimal estimation method (OEM) (Rodgers, 2000). Qpack 2 is designed specifically to work with ARTS, so one can perform forward modelling and retrieval work. Qpack 2 allows modelling of the instrument characteristics through sensor response matrices. The a priori volume mixing ratio (VMR) profiles used for the inversion of the KIMRA and MIRA 2 data are the Fast Atmospheric Signature Code (FASCOD) subarctic winter scenario profiles (Anderson et al., 1986). The temperature and pressure information (zpTs) up to $50 \mathrm{~km}$ is from daily National Centers for Environmental Prediction (NCEP) profiles, and above that is from the US Standard Atmosphere. The forward model pressure grid is 200 layers that are evenly spaced in altitude between ground level and approximately $100 \mathrm{~km}$. The retrieval pressure grid is 45 layers that are evenly spaced in altitude between ground level and approximately $90 \mathrm{~km}$. The retrieved quantity is the fractional VMR, the VMR of the target gas as a fraction of the a priori VMR for that gas. A polynomial of order 3 is included in the inversion and is fitted to each spectrum to account for some of the baseline waves. The inversions are non-linear and a Marquardt-Levenberg iterative root-finding method (Marquardt, 1963) is used with Qpack 2.

Attenuation of the signal due to water vapour, mainly in the troposphere, is accounted for with the Millimeter wave Propagation Model MPM93 $\mathrm{H}_{2} \mathrm{O}$ continuum (Liebe et al., 1993), which can be included in the forward modelling with ARTS. The spectroscopic parameters are taken from the HITRAN 2008 catalogue (Rothman et al., 2009). Estimates for the thermal measurement noise on each spectrum are obtained by fitting a second-order polynomial to a relatively flat part of the spectrum (covering 400 channels), and calculating the standard deviation of the residual for the fit. This value is used to calculate the measurement error covariance matrix (Rodgers, 1990). Error contributions from other instrumental and model parameters have previously been estimated for KIMRA and MIRA 2 using a modified OEM and so they have not been repeated here. For KIMRA, Raffalski et al. (2005) estimated that the uncertainty in the retrieved profiles due to baseline waves and systematic errors amounts to at least 1 ppmv. For MIRA 2, Kopp (2000) estimated an uncertainty of at least 1 ppmv is caused by errors due to baseline waves, systematic errors, and thermal noise. These error estimates are based on results of sensitivity tests and do not provide information about the structure of errors caused by "actual" baseline waves in the spectra. 

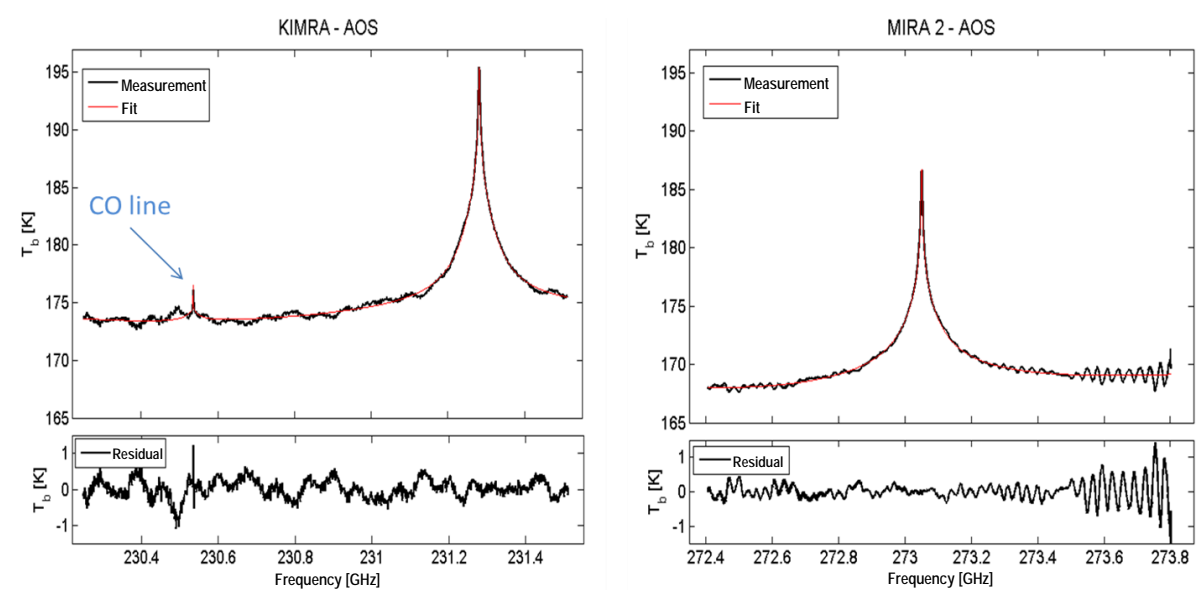

Figure 1. Example spectra and fits for a KIMRA_O ${ }_{3} \mathrm{CO}$ measurement and a MIRA 2 measurement. Note: the visible oscillatory pattern in the baseline of the MIRA 2 spectra has recently been eliminated after servicing of the AOS spectrometer.

\subsection{Example fits and properties of retrieved states}

Examples of fits to the data for a KIMRA_O ${ }_{3} \mathrm{CO}$ measurement and a MIRA 2 measurement are shown in Fig. 1. There are substantial baseline wave features in the spectra and the residua, often caused by internal reflections within an instrument. The clearly visible structure in the baseline of the MIRA 2 spectra (seen in Fig. 1) has been eliminated during recent servicing of the AOS. This structure was likely an artefact produced by a laser diode at the end of its life. There are some relatively short-scale baseline wave features in both the KIMRA and MIRA 2 data that would require the inclusion of a large-order polynomial in the baseline of the spectrum. Polynomial orders up to 9 were tried but no appreciable difference was found in the results. Since some oscillations were apparent in the retrieved profiles, it was decided to increase the estimate of the noise on the spectrum (Sect. 3.1) by a fixed amount, different for each instrument. This offset was estimated based on the amplitude of the baseline waves, but the final value was found by adjusting the offset until oscillations were not clearly visible in the retrieved $\mathrm{O}_{3}$ profiles. These oscillations are assumed to be due to the inversion fitting some fraction of the baseline wave features in the spectra, and while not clearly visible in a single profile, the results of the following sections show that the effect of the baseline waves is still present in the retrieved profiles.

The mean averaging kernels, measurement response, and altitude resolution for the retrieved profiles for each instrument are shown in Fig. 2. The actual averaging kernels, and quantities derived from them, will vary for each measurement depending mainly on the SNR of the spectrum. The retrieval altitude range is chosen using altitudes that have a measurement response higher than 0.8 . The choice of measurement response cut-off is somewhat arbitrary. A value of 0.8 is used here as it limits the contribution of a priori information in the retrieved profile and has been used for sev-
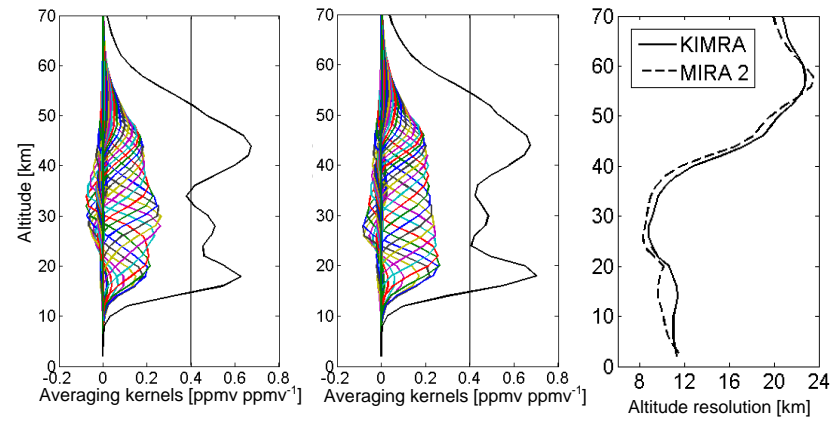

Figure 2. Left and middle: mean averaging kernels for KIMRA and MIRA $2 \mathrm{O}_{3}$ retrieved profiles used for the comparison. The measurement response divided by 2 is also shown as the solid black line. The vertical black line indicates a measurement response of 0.8. Right: the altitude resolution of the profiles, given by the full width at half maximum (FWHM) of the averaging kernels.

eral similar ground-based instruments (e.g. Hoffmann et al., 2011; Straub et al., 2010). This cut-off gives a range of approximately $16-54 \mathrm{~km}$. The mean measurement response for KIMRA dips just below 0.8 at $35 \mathrm{~km}$ due to some negative values in the corresponding averaging kernel but the inversion is still defined as useable here. The altitude resolution is, at best, $8 \mathrm{~km}$, and begins to degrade quickly above $40 \mathrm{~km}$ altitude. The values found here for MIRA 2 are very similar to previously shown values (Kopp, 2003). The degrees of freedom for signal (DOFS) over the retrievable altitude range for the retrieved states are approximately 4 for each instrument. 


\section{Comparison of KIMRA and MIRA 2}

\subsection{Coincidence criteria}

Since MIRA 2 always points north, only north-facing KIMRA measurements were used for this comparison. The measurement time and duration were used as follows to determine which profiles to compare to each other. For a given KIMRA measurement, it was determined whether there are any MIRA 2 measurements whose midpoint in measurement time lies within the duration of KIMRA's measurement. If so, it was determined which measurement has a longer duration (say it was MIRA 2). Then it was checked whether there were any more KIMRA measurements that also had a midpoint that lays within the duration of the MIRA 2 measurement. If so, the KIMRA profiles from all of these measurements were averaged to produce a single profile that was considered coincident with the corresponding MIRA 2 profile. If not, the two single profiles were considered coincident. This method compares profiles from measurements that overlap in time, and avoids using any measurement twice. There were $177 \mathrm{co}-$ incident sets that were identified for the following comparison. For the majority of the time, differences between coincident measurements are less than $1 \mathrm{~h}$. Measurement durations for each of the instruments range from $15 \mathrm{~min}$ to $4 \mathrm{~h}$, with a mean time of approximately $1 \mathrm{~h}$ for the coincident measurements.

\subsection{Results of KIMRA and MIRA 2 comparison}

Figure 3 shows the comparison of coincident KIMRA and MIRA $2 \mathrm{O}_{3}$ profiles for December 2012 to April 2013. Both average VMR profiles in Fig. 3 (left) have lower values than the a priori VMR except for below about $18 \mathrm{~km}$. The mean difference (KIMRA-MIRA 2) in the profiles shows an oscillatory structure. KIMRA is generally low-biased with respect to MIRA 2 except for a peak at $30 \mathrm{~km}$ and the largest negative value is a peak of $-1.1 \mathrm{ppmv}$ at $22.5 \mathrm{~km}$. The standard deviation of the differences is largest between 26 and $34 \mathrm{~km}$. The standard error of the mean difference is also shown but is small due to the sample size. There is a strong correlation of the VMR values $(\sim 0.95)$ above $35 \mathrm{~km}$. This decreases to about 0.85 at $30 \mathrm{~km}$ and then drops rapidly to a minimum below 0.50 at $26 \mathrm{~km}$. Within $17-24 \mathrm{~km}$ the correlation is above 0.70 before decreasing to $\sim 0.50$ at the lower retrieval limit.

Since there are approximately 4 DOFS for each measurement, the $\mathrm{O}_{3}$ profiles were split into four altitude regions, and the total $\mathrm{O}_{3}$ concentration (in molecules $\mathrm{cm}^{-2}$ ) was calculated for each region, corresponding to four $\mathrm{O}_{3}$ partial columns. The column densities were calculated using the temperature profiles from the zpTs and the ideal gas law. The altitude ranges of the four partial columns are 16-26, 26-36, 36-46, and 46-56 km (the numbers are the centres of the retrieval grid layers), and each region corresponds to approximately 1 DOFS. The correlations of the $\mathrm{O}_{3}$ partial
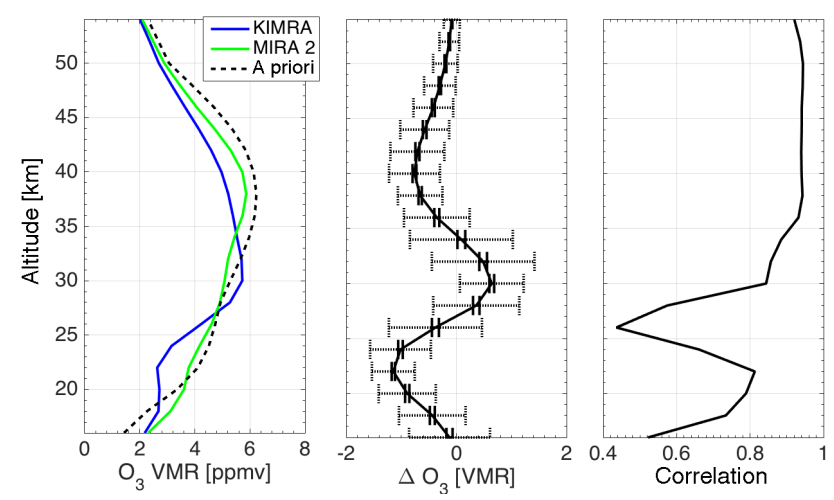

Figure 3. Left: the average of the 177 coincident $\mathrm{O}_{3}$ profiles for KIMRA and MIRA 2 and the a priori profile used for the inversions. Middle: the mean of the difference (KIMRA-MIRA 2) for coincident profiles. The solid error bars are the standard error of the mean, and the dotted error bars are the standard deviation of the differences in the profiles at each altitude. Right: the correlation of the coincident pairs at each altitude.

column concentrations were calculated, and a line of best fit was determined for each column. The fit was determined using a linear regression for data with errors in both the $X$ and $Y$ variables, following York et al. (2004). The regression coefficients (slope and intercept) are calculated for two cases of KIMRA/MIRA 2 partial column error estimates. The first case includes only the measurement error on the profile: the error due to the statistical noise on the spectrum (Rodgers, 1990), to which an offset has been added to account for short scale waves in the spectral baseline (see Sect. 3.2). The second case is the sum of $130 \%$ measurement error and the mean of the measurement errors on each partial column; the former increase is to try to account for other errors that vary statistically (such as errors in the temperature profile), and the latter is to include an error that does not change in magnitude over time or depend on an individual observation. The idea here is that this will help to capture some of the variation in the measurements that is neither truly random nor systematic in nature, such as a baseline error. While not based on it, the larger error estimate appears justified when one considers the bias shown in Fig. 3. The limits of these slopes and their standard errors define a range that should contain the value of 1 if the measurements agree. A similar approach was used by Nedoluha et al. (1997), in which case the standard deviation of the satellite measurements being compared was added to the errors of the ground-based measurements.

The results for KIMRA and MIRA 2 are plotted in Fig. 4, showing the correlations and the slopes and intercepts of the lines of best fit in each case. The correlations between the partial columns are high, even for layers containing the altitudes with poor profile correlation (Fig. 3; right), with 36$46 \mathrm{~km}$ having the highest value of 0.97 . A value of 1 lies within the range of the slopes calculated for the two lowermost columns, albeit just barely for the $16-26 \mathrm{~km}$ column. 

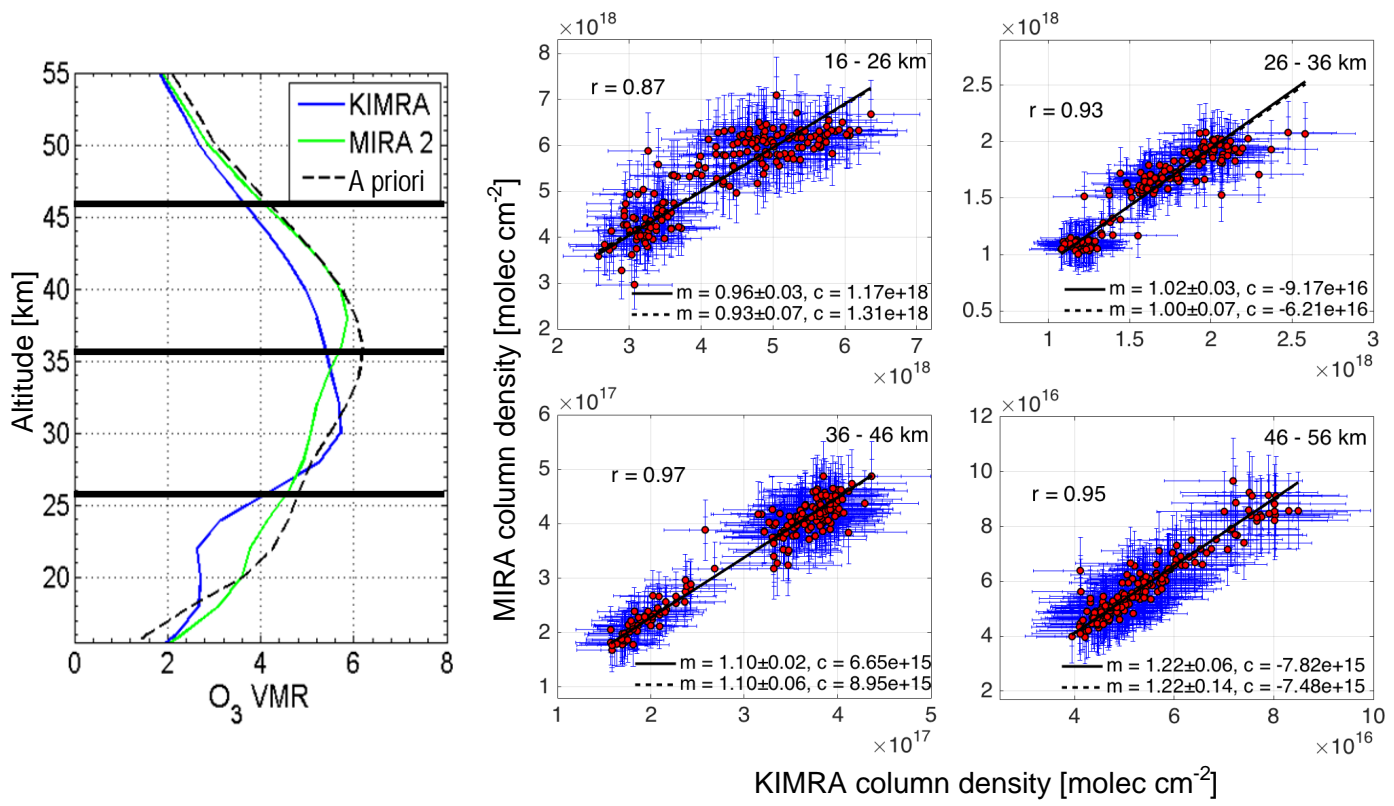

Figure 4. Left: same as left plot in Fig. 3 (in ppmv) but with markers showing the altitude separation of the partial columns. Right: scatter plot of the partial columns of coincident KIMRA and MIRA 2 data. The error bars show the two cases of error estimation for the ground-based instruments (see Sect. 4.2). Lines of best fit are shown for each case, with the dashed line indicating the case of the higher error estimate. The slope $(\mathrm{m})$ and its standard error, and the intercept $(\mathrm{c})$ for each line are shown. The correlation for each of the sets of partial columns is also shown.

The 26-36 km columns agree for both cases of error estimation. A value of 1 does not lie in the range of slopes for the two higher partial columns, with MIRA 2 showing a larger range of $\mathrm{O}_{3}$ values in both cases. A value of 1 for the slope does lie in twice the standard error range of the higher error estimates, but for the $46-56 \mathrm{~km}$ partial column this error is likely an overestimation as the error bars are larger than the variation of the points from the line of best fit.

With just the data from these two instruments, it is difficult to diagnose the reason for the bias in the profiles; however, the oscillatory structure in the mean difference of KIMRA and MIRA 2 profiles (Fig. 3; middle) is present in all of the individual difference profiles. This suggests a systematic error. It is reasonable to assume that this error arises from the clear non-spectral line structures present in the spectra (see Fig. 1), i.e. baseline waves. These structures are often due to standing waves in the instruments. Baseline waves that have a scale similar to that of the spectral lineshape are the most difficult to separate from the sky signal, especially if a baseline wave is symmetric about the line centre. For this reason, it is assumed that the baseline waves in the KIMRA measurements will have more of an impact on the retrieved $\mathrm{O}_{3}$ state than the those in the MIRA 2 spectra, which have a shorter scale in frequency space. Part of the variation in the differences between individual profiles would also be explained with baseline waves as the cause, for the following reason: the retrieved ozone state is affected by the opacity of the atmosphere. If some of the baseline waves in the spec- trum are incorrectly attributed to a concentration of ozone at some altitude in the atmosphere, then that contribution to the retrieved state will also vary depending on the atmospheric opacity. A higher opacity will mean that the inversion attributes a greater atmospheric concentration to the baseline wave in the spectrum.

\section{Comparison with ozonesondes and MLS}

KIMRA and MIRA $2 \mathrm{O}_{3}$ profiles were compared to profiles from ozonesondes launched at Sodankylä, Finland $\left(67.37^{\circ} \mathrm{N}, 26.63^{\circ} \mathrm{E}\right)$. The ozonesondes are launched by the Finnish Meteorological Institute at Sodankylä. The location of the launches is a good site for a comparison as it has a similar latitude to IRF $\left(67.84^{\circ} \mathrm{N}\right)$, and the meridional gradient of $\mathrm{O}_{3}$ tends to be greater than the zonal gradient. Thirty-one ozonesonde measurements were provided for this study. The data are from between 31 October 2012 and 29 May 2013, and the sondes were launched approximately once per week. The instruments are electrochemical concentration cell (ECC) sondes, using a potassium iodide solution. The partial pressure of $\mathrm{O}_{3}$ is calculated according to an electrical current produced by the reaction between $\mathrm{O}_{3}$ and iodide (Kivi et al., 2007; Smit et al., 2011). Overall uncertainty of the ozone measurements by ECC sondes in the stratosphere is about $5 \%$ (Deshler et al., 2008; Hassler et al., 2014). In Sodankylä the sonde preparation procedures have followed the generally accepted recommenda- 
tions (Smit et al., 2011). The sounding system is DigiCORA III from Vaisala. The radiosondes are RS92-SGP (Dirksen et al., 2014). The radiosondes measure pressure, temperature, humidity, and wind profiles during the balloon ascent and descent. Ozone data are transmitted using the Vaisala Digital Interface OIF92. The sondes used in this work have maximum measurement altitudes ranging from 18 to $34 \mathrm{~km}$, with an effective altitude resolution of the order of 100-150 m. The vertical resolution depends on the balloon ascent rate and the sensor response time. The ascent rate is typically $5 \mathrm{~m} \mathrm{~s}^{-1}$ and the response time of the ozone sensor is 20-30 s.

The Microwave Limb Sounder (MLS) is one of four instruments aboard the Aura satellite. The satellite is part of the National Aeronautics and Space Administration's (NASA) Earth Observing System. The MLS scans are synchronised to the orbit and measurements are at approximately the same time at the same latitude each day, spaced in distance by roughly $165 \mathrm{~km}$ on the suborbital track. The $\mathrm{O}_{3}$ measurements used in this work are made using the spectral lines in the $240 \mathrm{GHz}$ band. More details on the instrument and observation technique are found in Waters et al. (2006). The v3.3/v3.4 version of the level 2 data was used in this comparison (Livesey et al., 2013). Gas concentrations are retrieved on a 55-layer pressure grid. The ozone profiles have a vertical resolution of $\sim 3 \mathrm{~km}$ from $261-0.2 \mathrm{hPa}$, and $4-5.5 \mathrm{~km}$ from 0.1 to $0.02 \mathrm{hPa}$. These levels cover the "useful range" of the data quoted by the MLS team (Livesey et al., 2013). The precision of the measurements is $\sim 0.04 \mathrm{ppmv}$ from $215-46 \mathrm{hPa}$, $0.1-0.5 \mathrm{ppmv}$ from $22-0.1 \mathrm{hPa}$, and $1.4 \mathrm{ppmv}$ from $0.05-$ $0.02 \mathrm{hPa}$. The validation of the previous v2.2 data has been documented in Jiang et al. (2007), Froidevaux et al. (2008), and Livesey et al. (2008).

\subsection{Coincidence criteria}

Time, distance, and position relative to the polar vortex were the criteria used in determining which individual profiles to compare, and are described here for each instrument. The location of a measurement with respect to the polar vortex was determined using scaled potential vorticity (sPV) values (Manney et al., 2007). For the ground-based instruments the values were calculated geometrically along the instrument's line of sight. An sPV value of $1.4 \times 10^{-4} \mathrm{~s}^{-1}$, or nearby values, have been used extensively in previous works (e.g. Manney et al., 1994a, 2007, 2011; Jin et al., 2006) to define the vortex edge centre. Values of 1.6 and $1.2 \times 10^{-4} \mathrm{~s}^{-1}$ have been used in the cited works to define the inner and outer edges, respectively, and the same values are used here. Both the north- and south-pointing measurements from KIMRA are used in the following comparisons.

The general procedure for ozonesondes vs. KIMRA/MIRA 2 and MLS vs. KIMRA/MIRA 2 comparisons was as follows. For a given ozonesonde/MLS measurement, a maximum limit on the difference in time between measurements was used to choose a group of possi- ble KIMRA/MIRA 2 measurements with which to compare. This group was reduced to those measurements that were in the same location as the ozonesonde/MLS measurement, relative to the polar vortex (inside vortex/outside vortex/in vortex edge). From this new group, the closest measurement in space, using distance along a great circle, was chosen as the measurement for comparison. Each KIMRA/MIRA 2 measurement was only used once in a comparison with another instrument.

For MLS, a maximum time difference of $\pm 4 \mathrm{~h}$ between measurements was used. A small time limit was preferred, and it was decided that less than $4 \mathrm{~h}$ produced too few coincidences, while more than $4 \mathrm{~h}$ did not make a significant difference to the number of coincidences. Either way, the choice of time criterion did not have a substantial effect on the presented comparison results (there was a slight increase in standard deviation of the differences for a looser time coincidence). For the distance criterion, the closest measurement in space had to lie within a given latitude and longitude box: $\pm 2^{\circ}$ latitude and $\pm 10^{\circ}$ longitude. A smaller longitude box of $\pm 5^{\circ}$ was also tried but it halved the number of coincidences and made no significant difference to the results. The altitude at which the distance between measurements was calculated is $34 \mathrm{~km}$. The reason for the choice is that this altitude coincides approximately with the peak in the $\mathrm{O}_{3}$ VMR profile above Kiruna, and it is also approximately the middle of the retrievable altitude range for the ground-based instruments. The altitude used for the SPV criterion for the MLS comparisons was $34 \mathrm{~km}$, the same as that used for the distance criterion, explained above.

For the ozonesondes, no criterion was placed on the measurements with respect to their distance from KIMRA/MIRA 2 measurements. It is assumed that the location of the sonde $\mathrm{O}_{3}$ profiles is above the launch station in Sodankylä. For the time criterion, the closest KIMRA/MIRA 2 measurement within $24 \mathrm{~h}$ was used to compare to the ozonesonde profile, although the selected profile was almost always within a few hours of a ground-based measurement. As the sonde profiles have differing maximum altitudes, the resulting comparisons have different numbers of coincident points for different altitudes. For the ozonesonde comparison, the criterion for sPV was applied at an altitude of $18 \mathrm{~km}$ for the following reasons: $18 \mathrm{~km}$ is the lowest maximum altitude of the used sondes, and it is the only altitude that is common to every sonde.

Both the ozonesonde and MLS profiles were smoothed (Rodgers and Connor, 2003) using the averaging kernels of the coincident KIMRA/MIRA 2 measurements before they were compared so that the profiles would have similar resolution. The effect of excluding $\mathrm{O}_{3}$ measurements in the edge of the vortex was examined for each comparison and discussed in the following sections. 

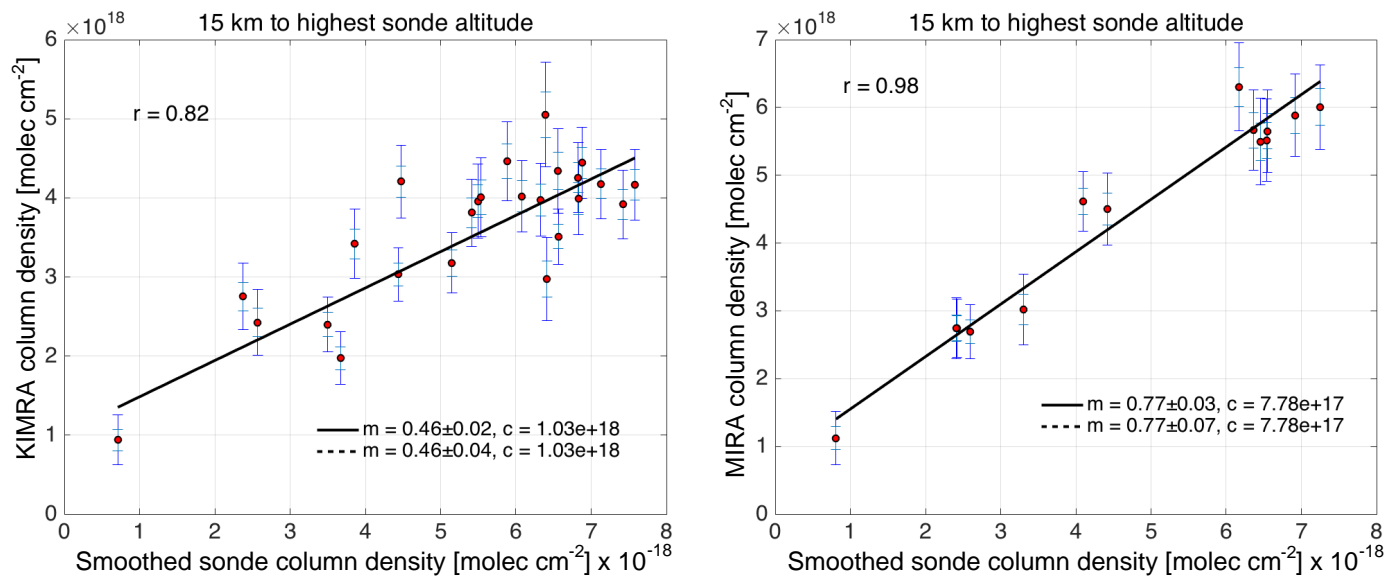

Figure 5. Left: scatter plot of the KIMRA O 3 partial columns against Sodankylä ozonesonde partial columns from November 2012 through to May 2013. The line of best fit is shown with the accompanying correlation coefficient. The slope $(m)$ and its standard error, and the intercept $(c)$ for each line are shown. Error bars and lines of fit are shown for two cases of error estimation for KIMRA, as in Fig. 4. Right: the same as left plot but for MIRA 2 and Sodankylä ozonesonde measurements from December 2012 through to April 2013.

\subsection{Results of comparison with ozonesondes}

Since the ozonesondes cover varying altitude ranges, it was decided that it was most appropriate to compare partial columns (calculated from $15 \mathrm{~km}$ to the maximum sonde altitude) with the ground-based data. The densities for KIMRA and MIRA 2 data were calculated as in Sect. 4.2 but the column heights were chosen to match the maximum heights of the coincident ozonesondes. The densities for the ozonesonde data were calculated using the smoothed $\mathrm{O}_{3}$ profiles and the temperature measurements made by the sondes during their flight. Because the ground-based measurements have some sensitivity to $\mathrm{O}_{3}$ at altitudes higher than the reach of the sondes, the sonde profiles were extended above their maximum altitudes prior to performing the smoothing calculation. This was done using the a priori concentrations (Sect. 3.1) scaled to match the sonde data at its highest altitude. Figure 5 shows the partial column densities from the ozonesondes plotted against the respective coincident measurements for KIMRA and MIRA 2. A linear regression was performed assuming that the ozonesonde data are true, and using the two cases of error estimation for KIMRA and MIRA 2 that are defined in Sect. 4.2.

The line of best fit to the scatter plot of the KIMRA and sonde data gives a slope of 0.46 , and a correlation coefficient of 0.82 . For MIRA 2, the slope of the line of best fit is 0.77 and there is a high correlation coefficient of 0.98 . While there is good correlation, the results suggest that both KIMRA and MIRA 2 measurements of lower stratospheric $\mathrm{O}_{3}$ are likely affected by baseline errors that are not fully characterised by the error estimates here, KIMRA more so than MIRA 2.

Figure 6 shows the sPV value for measurements made by each instrument at altitudes of 18,24 , and $30 \mathrm{~km}$. The similarity of the sPV for the ground-based instruments and

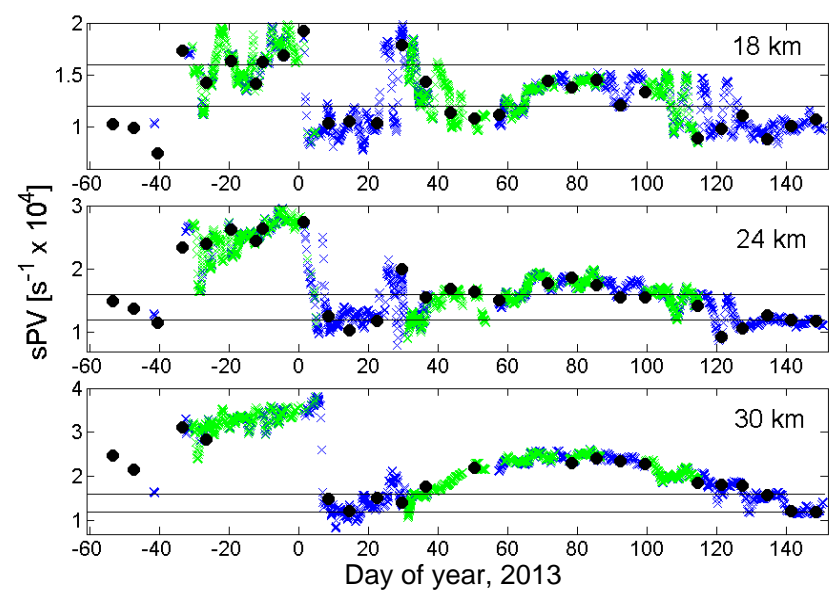

Figure 6. The SPV value corresponding to the measurement locations of KIMRA (blue X), MIRA 2 (green X), and Sodankylä ozonesondes (black dot), at altitudes of 18,24 , and $30 \mathrm{~km}$. Lines of sPV values of 1.2 and $1.6 \times 10^{-4} \mathrm{~s}^{-1}$, respectively defining the outer and inner edge of the polar vortex, are also shown.

the ozonesondes confirms Sodankylä as a reasonable comparison site for Kiruna. Most likely due to the location of both sites, the variability of sPV between altitudes shows that the measurements sometimes simultaneously detect $\mathrm{O}_{3}$ concentrations from inside, outside, and within the edge of the polar vortex, depending on the respective altitudes. This makes the task more difficult when comparing measurements. Since the largest concentration gradients lie within the vortex edge, the results were examined to see whether it made a difference if all $\mathrm{O}_{3}$ profiles that lie in this region $\left(1.2 \times 10^{-4} \mathrm{~s}^{-1}<\mathrm{sPV}<1.6 \times 10^{-4} \mathrm{~s}^{-1}\right)$ were excluded. The number of coincidences decreased from 25 to 17 for KIMRA. The partial column correlation remained at 0.82 , and the 

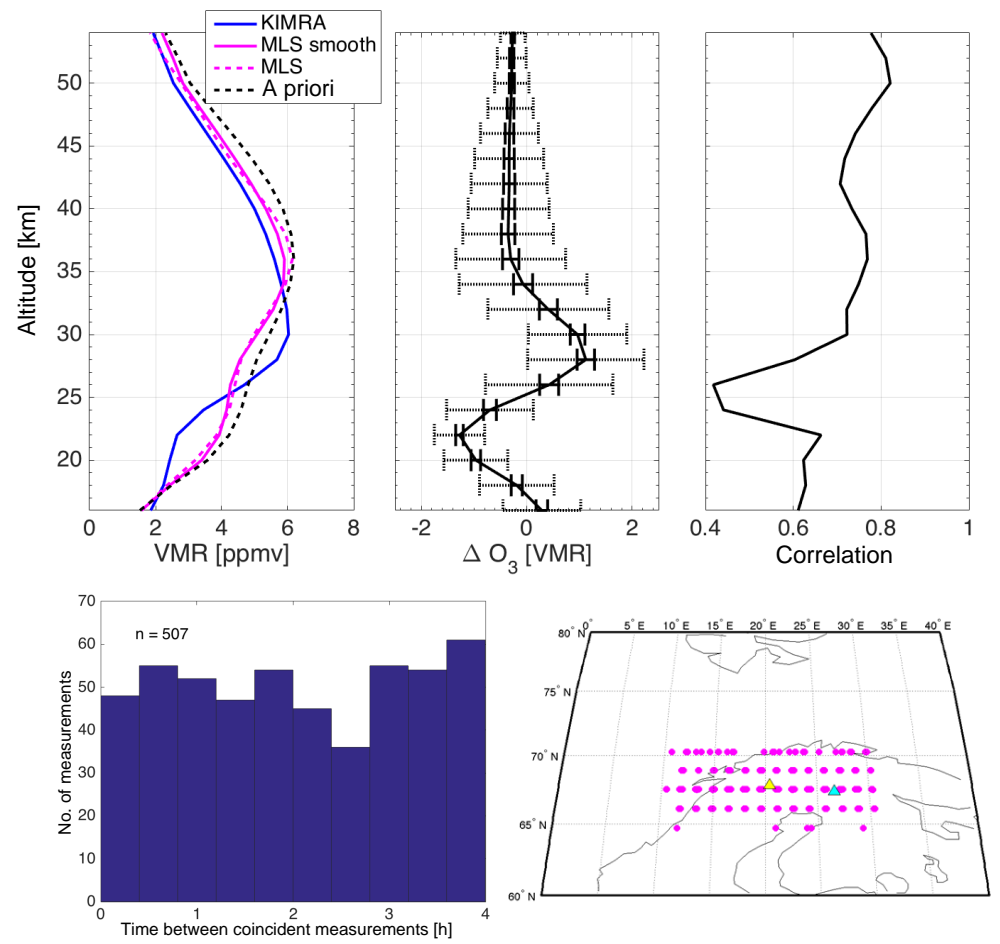

Figure 7. Upper row: the same as for Fig. 3, but for KIMRA-MLS. Both the average of the smoothed (used for comparison) and unsmoothed MLS profiles are shown here. Lower left: histogram of the time difference between coincident measurements. Lower right: map showing the locations of the coincident MLS measurements (magenta circles), Kiruna (yellow triangle), and Sodankylä (cyan triangle).

slope of the line of best fit changed from $0.46 \pm 0.02 / 0.04$ to $0.47 \pm 0.02 / 0.04$ (standard error for smaller/larger error bars). The change for MIRA 2 was more dramatic: the number of coincidences decreased from 14 to 7 . The partial column correlation increased from 0.98 to 0.99 , and the slopes of the line of best fit changed from $0.77 \pm 0.03 / 0.07$, to $0.88 \pm 0.04 / 0.10$. Although there are only seven coincidences, these numbers indicate a good agreement in the MIRA 2 and ozonesonde partial columns.

\subsection{Results of comparison with MLS}

Results of the profile comparison with MLS are shown in Fig. 7 for KIMRA and in Fig. 8 for MIRA 2 for the period of December 2012 through to April 2013. There are 507 coincident measurements for KIMRA and 394 coincident measurements with MIRA 2. Above $35 \mathrm{~km}$, KIMRA has a good agreement with MLS with a consistent low bias of $\sim 0.3$ ppmv. Below that, the oscillatory bias seen in the comparison with MIRA 2 (Fig. 3; middle) is present, with a maximum/minimum of approximately \pm 1 ppmv. The steep drop in the correlation for KIMRA is also seen again (see Fig. 3; right) at approximately $26 \mathrm{~km}$. In Fig. 8 MIRA 2 shows better agreement with MLS. There is a general high bias below $47 \mathrm{~km}$, with an oscillatory structure peaking at approximately $0.6 \mathrm{ppmv}$ at the lowest retrievable altitude for MIRA 2. The correlation is above 0.90 for altitudes above $35 \mathrm{~km}$ and de- creases to about 0.70 at the lowest retrieval altitude range of MIRA 2. Standard error of the mean difference is again very small because of the large sample size.

In the time series comparisons in Figs. 9 and 10, the profiles are split into four partial columns corresponding to the same altitude ranges as in Fig. 4. The partial columns for MLS were calculated using the MLS temperature measurements that are coincident with the MLS $\mathrm{O}_{3}$ measurements. There is a clear increase in the column densities at the beginning of January that is shown by both KIMRA and MLS columns, and there is unfortunately a data gap here for MIRA 2. The ground-based time series appear to follow MLS well in monthly and sub-daily variation, with fewer outlying values for MIRA 2 than for KIMRA. There are some likely unphysical outliers in the KIMRA data that can be seen in both plots in Fig. 9, but there has been no reason yet to eliminate them.

Lines of best fit were calculated, accounting for errors in $X$ and $Y$. The correlations between KIMRA and MLS (Fig. 9; lower) vary between 0.66 and 0.80 , and slopes of best fit for the partial columns vary between 0.81 and 0.96 , for the case of the lower error estimate. Only for the lowermost column does a value of 1 lie in twice the standard error range of the calculated slopes, but it should be noted that the slopes for the lower error estimate all lie within $19 \%$ of 1 . The correlations between MIRA 2 and MLS (Fig. 10; lower) are high, 

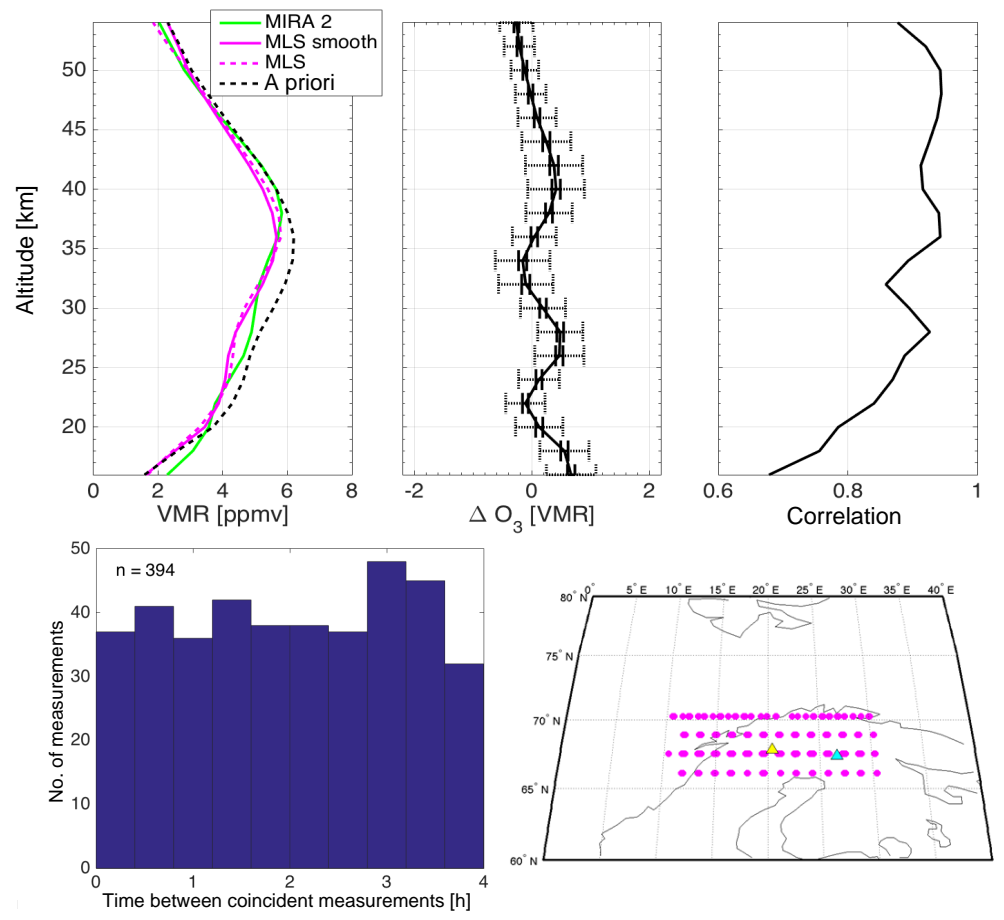

Figure 8. The same as Fig. 7 but for MIRA 2-MLS.

between 0.88 and 0.94 , and a value of 1 lies in the range of calculated slopes for the two lowermost columns. It can be seen from the two $46-56 \mathrm{~km}$ panels in Fig. 10 that MIRA 2 is low-biased in the case of high $\mathrm{O}_{3}$ columns at these altitudes.

In most instances for the comparisons with MLS, the higher error estimate has a small change $(<0.03)$ on the value of the calculated slopes, but a large change is seen for the two highest columns in the KIMRA and MLS comparison in Fig. 9 (lower). This is likely due to the smaller natural variation in $\mathrm{O}_{3}$ at these altitudes and the presence of outliers in the KIMRA data. MIRA 2 in general shows better agreement with MLS, compared to KIMRA.

Figure 11 shows the sPV values at $34 \mathrm{~km}$ for all KIMRA and MIRA 2 measurements, and all coincident MLS data. One can see that no MIRA 2 measurements lie within the edge of the polar vortex during the time range. When excluding the vortex edge data from the KIMRA comparison, the absolute change in the calculated slopes is $<0.04$ and the change in correlations is $<0.04$, except for the lowermost column, which showed an increase in correlation from 0.66 to 0.73 .

The $\mathrm{O}_{3}$ profiles from all the KIMRA, MIRA 2, and unsmoothed MLS measurements from December 2012 through April 2013 were averaged by day. The daily averages are plotted against time in Fig. 12. Each dataset shows a similar evolution of $\mathrm{O}_{3}$ over the winter: the generally low stratospheric $\mathrm{O}_{3}$ concentration in December, a rapid increase in early January, and the descent of high $\mathrm{O}_{3}$ concentration air, by about $10 \mathrm{~km}$ lower in altitude, through March and April. The differences in the profiles, found in Sect. 4.2, can also be seen: the low bias in KIMRA $\mathrm{O}_{3}$ at $\sim 22 \mathrm{~km}$ is apparent, and also the high bias at $\sim 28 \mathrm{~km}$, most easily noticeable in December and January. The higher MIRA 2 profile values around $40 \mathrm{~km}$ are attributed to a high bias of $\sim 0.5 \mathrm{ppmv}$ in the MIRA 2 data at this altitude; this conclusion is reached by comparing the differences in the KIMRA and MIRA 2 data (Fig. 3) as well as their respective differences with MLS (Figs. 7 and 8).

It is important for the following section to see that the apparent "dip" in the $\mathrm{O}_{3}$ profile, that one can see between approximately $35 \mathrm{~km}$ (January) and $28 \mathrm{~km}$ (March), is present in each dataset and is not a result of the oscillatory structure in the KIMRA dataset. The high bias in KIMRA $\mathrm{O}_{3}$ at $\sim 28 \mathrm{~km}$ may make this dip more pronounced, but the low bias in KIMRA $\mathrm{O}_{3}$ occurs at a lower altitude: $\sim 22 \mathrm{~km}$. As the location in altitude of this local minimum can change throughout the winter, due to descent of air for instance, the oscillatory bias in the KIMRA profile can either enhance or obscure its presence. Thus, it will be challenging to accurately identify a local minimum feature with KIMRA data alone. It is assumed from this point on that the KIMRA O data have a low bias of $1 \mathrm{ppmv}$ at $\sim 22 \mathrm{~km}$ and a high bias of $1 \mathrm{ppmv}$ at $\sim 28 \mathrm{~km}$, each maximum with a half width of $\sim 5 \mathrm{~km}$. 

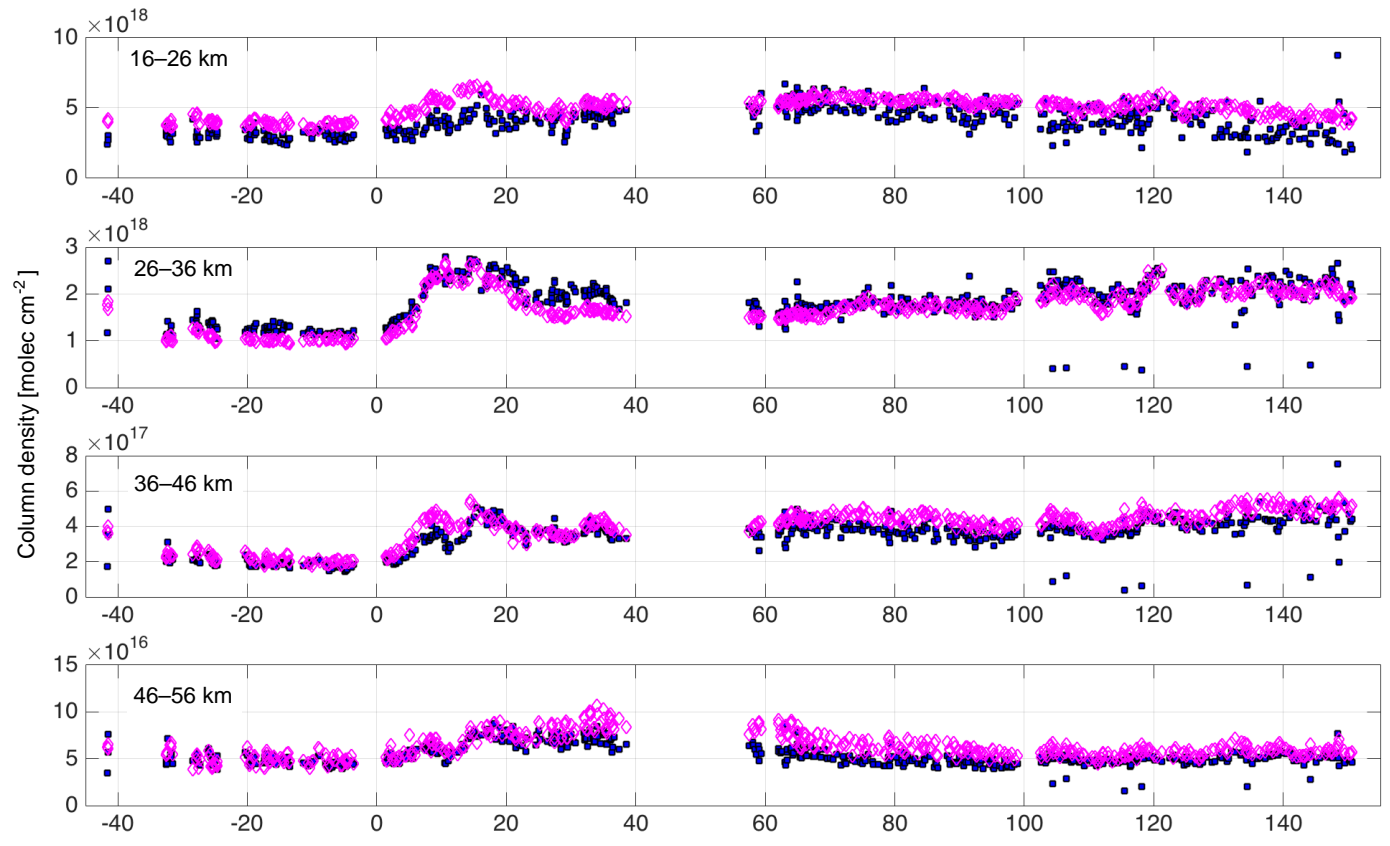

Day of the year 2013
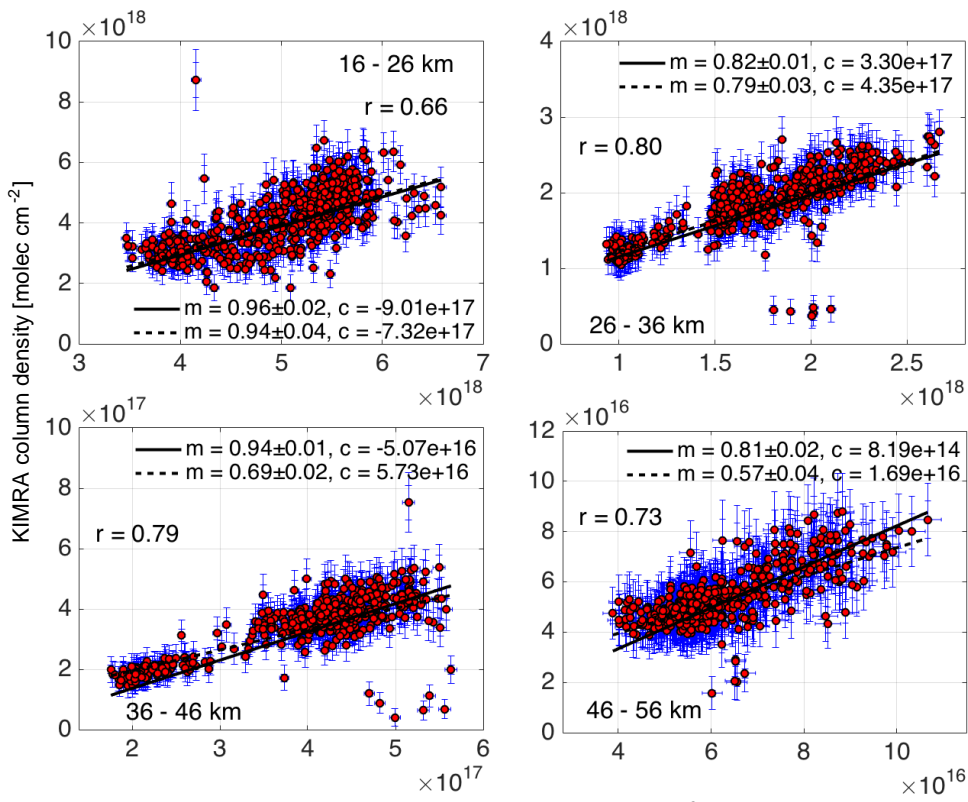

MLS column density [molec $\mathrm{cm}^{-2}$ ]

Figure 9. Upper: the $\mathrm{O}_{3}$ partial column densities from KIMRA (blue filled squares) and coincident MLS (hollow magenta diamonds) measurements plotted against time. Lower: scatter plots of the corresponding coincident data. Error bars and lines of fit are shown for two cases of error estimation for KIMRA, as in Fig. 4. The slope $(m)$ and its standard error, and the intercept $(c)$ for each line and correlation coefficients are also shown.

\section{The KIMRA dataset: daily variability in wintertime ozone above Kiruna}

This section moves on from the comparisons between datasets into an examination of the KIMRA dataset over 5 years between 2008 and 2013, by looking at the daily variability of wintertime $\mathrm{O}_{3}$ above Kiruna. Because one cannot definitively explain the variations in $\mathrm{O}_{3}$ profiles at one location without using other data and/or model output, and that is not the aim of this work, only some general observations are made. 

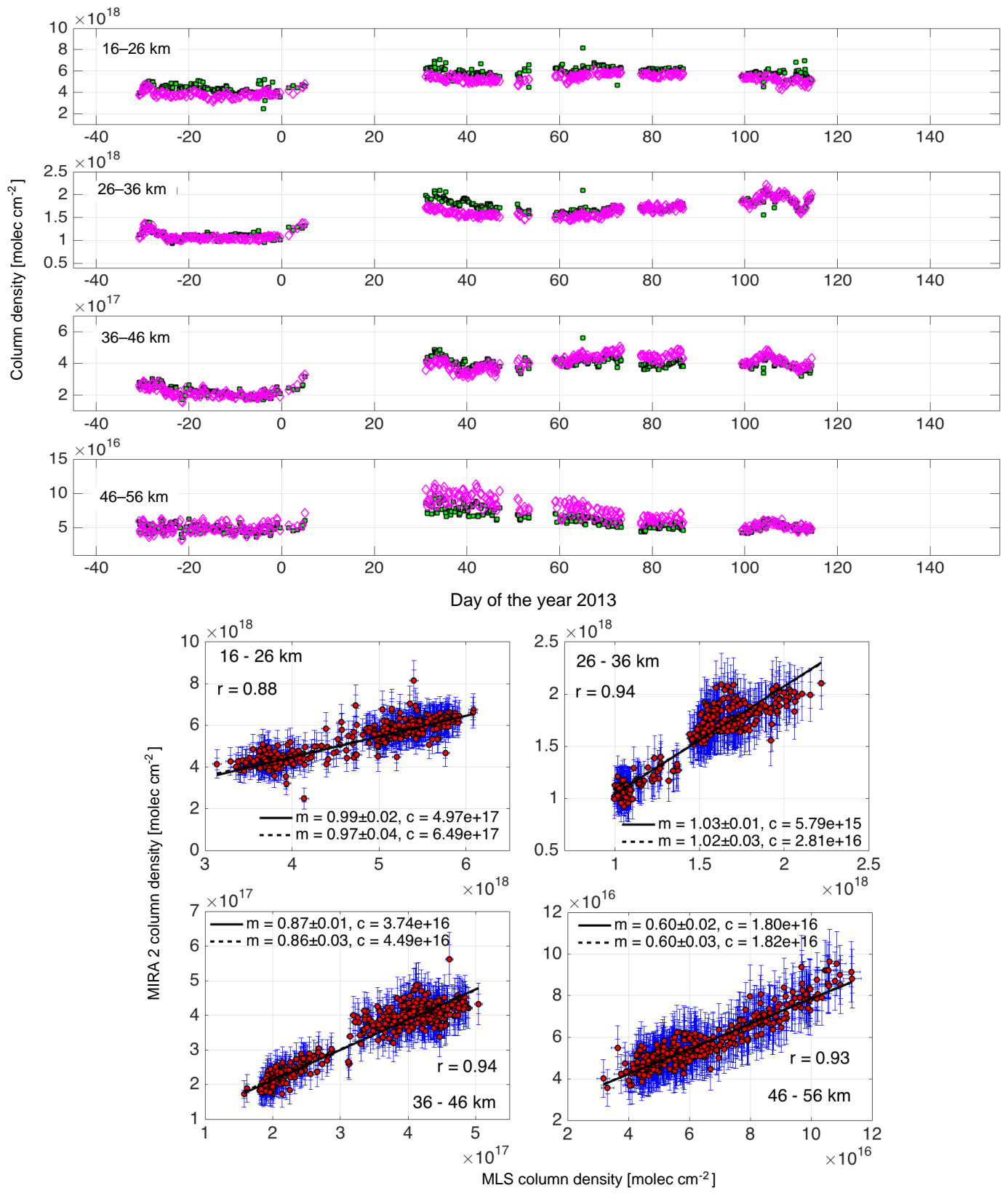

Figure 10. Same as Fig. 9 but for MIRA 2 (green filled squares) and MLS (hollow magenta diamonds).

\subsection{January to March, 5-year $\mathrm{O}_{3}$ time series}

$\mathrm{O}_{3}$ profiles have been retrieved from KIMRA measurements for January, February, and March, from 2008 to 2013. Data were not available from 2012. Daily averages were made and the resulting time series for each year are shown in Fig. 13. January predominantly shows the lowest $\mathrm{O}_{3}$ concentrations, except for in one region at around $30 \mathrm{~km}$ (particularly for 2009 and 2013), which has a sharp maximum. The sharp rise in $\mathrm{O}_{3}$ concentrations in January 2009 and 2013 coincides with strong "major" sudden stratospheric warmings (SSWs) that started on 24 and 6 January in those years, respectively, and broke down the vortex for about 1 month (e.g. Manney et al., 2015). There was a similar SSW in 2010 that began on 26 January, and the KIMRA data show an increase in midstratospheric $\mathrm{O}_{3}$ concentrations a few days later. The increase in concentrations in late February 2008 also coincides with a brief SSW that occurred at that time. The most interesting feature is the aforementioned dip in the profile. The $\mathrm{O}_{3}$ dip is present for some period of time each year, and disappears in late February or March. It is persistent up to the end of March in 2009. It is very unlikely that this feature is caused by chemical ozone depletion as ozone loss result- 


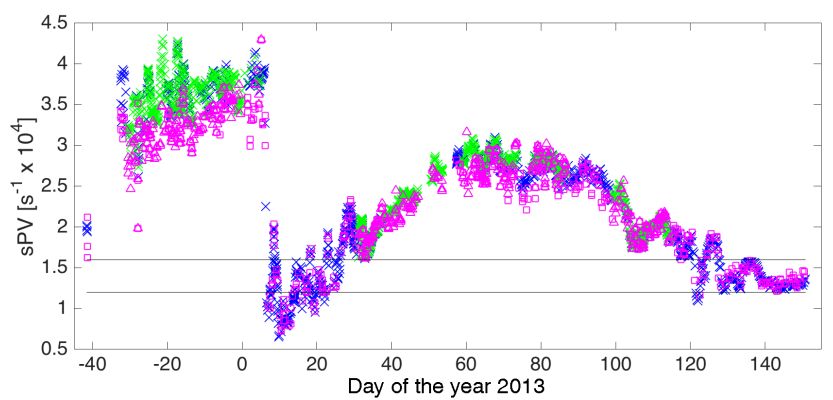

Figure 11. $\mathrm{sPV}$ values at $34 \mathrm{~km}$ at the location and time of all KIMRA measurements (blue X), and coincident MLS measurements (magenta square). The same is shown for all MIRA 2 measurements (green X) and coincident MLS measurements (magenta triangle). The black lines indicate the edges of the polar vortex (see Fig. 6).

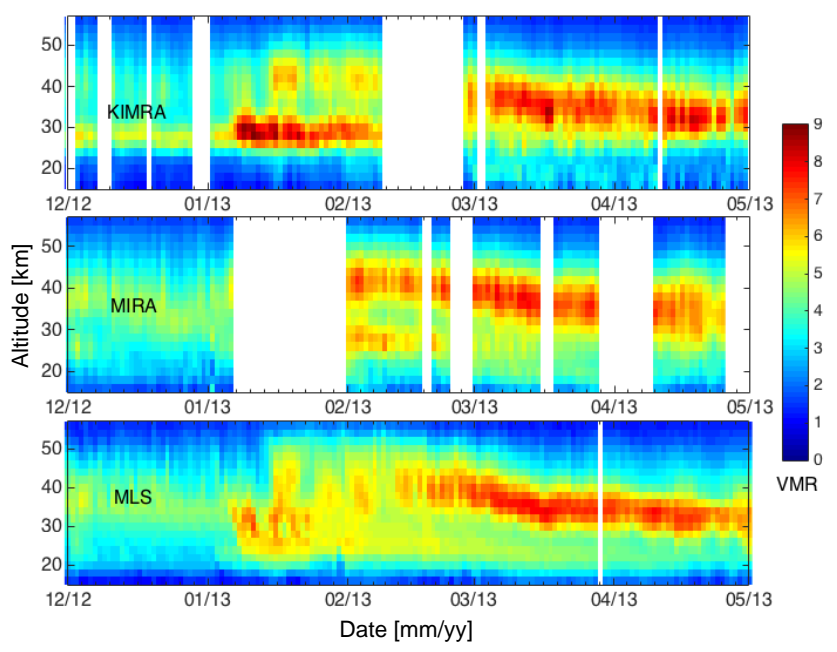

Figure 12. Time series of the daily average $\mathrm{O}_{3}$ profiles (in ppmv) for KIMRA, MIRA 2, and unsmoothed MLS measurements.

ing from heterogeneous reactions in the lower stratosphere has never been seen extending to this altitude in the Arctic (e.g. Manney et al., 2003, 2015; Kuttippurath et al., 2010; Livesey et al., 2015). A strong $\mathrm{O}_{3}$ dip (most similar to 2010 presented here) has been observed previously with KIMRA, in the winter of 2002/2003 (Raffalski et al., 2005). This coincided with ozone mini-holes between 4 and 11 December 2002, as reported by the European Ozone Research Coordinating Unit and discussed in Raffaslski et al. (2005), but the KIMRA measurements presented for that winter still show the structure of an $\mathrm{O}_{3}$ dip throughout most of December. The latitudinal extent of the polar vortex has been shown to vary with altitude (e.g. Schoeberl et al., 1992; Manney et al., 1995; Harvey et al., 2002), which could explain an occurrence of a local minimum/maximum, but such a feature would not remain stable long enough to account for the observations shown here. A possible explanation for the observed shape is

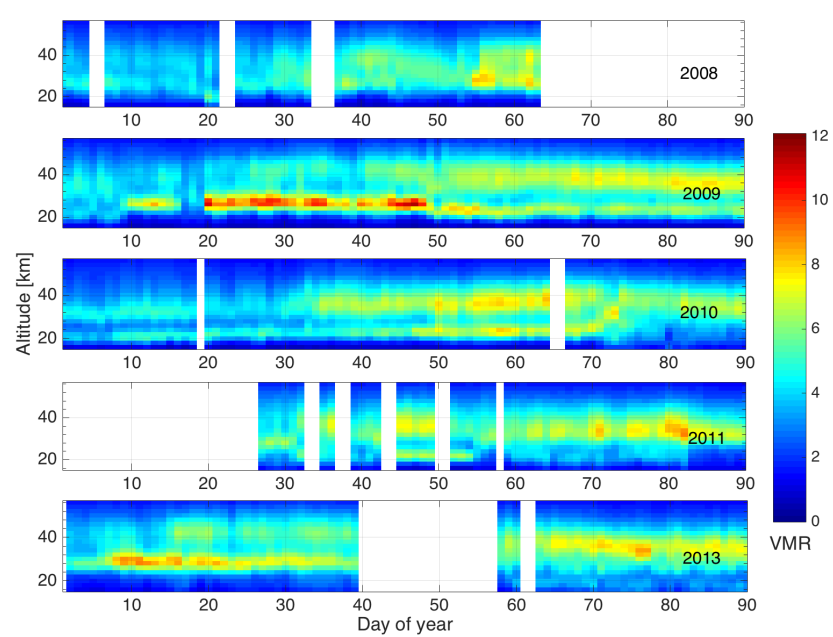

Figure 13. Retrieved daily averaged $\mathrm{O}_{3}$ concentrations (in ppmv) above Kiruna from KIMRA, for January to March for the years 2008, 2009, 2010, 2011, and 2013.

the combination of downward motion of air within polar vortex, and transport of extra-vortex air into the middle to upper stratosphere, due to wave activity, for instance (e.g. Manney et al., 1994b, 1995, and 2015; Kuttippurath et al., 2012). The downward motion of vortex air would increase $\mathrm{O}_{3}$ concentrations in the lower stratosphere, and the transport of extravortex air would increase $\mathrm{O}_{3}$ concentrations in the middle to upper stratosphere. This could give a local minimum in between, but the timing and extent of these processes can vary strongly interannually (see references in this section), and so further study is needed.

The monthly average of daily mean $\mathrm{O}_{3}$ profiles for each year is shown in Fig. 14, as well as the overall multi-year mean and standard deviation. For each month, $\mathrm{O}_{3}$ shows the most variability in the middle stratosphere, between approximately 20 and $33 \mathrm{~km}$. Some of the variation may be due to the fact that KIMRA switches its observation direction between north and south, but the daily averaging of the profiles should remove much of it. Additionally, as discussed in Sect. 4.2, the baseline waves in the $\mathrm{O}_{3}$ spectra will cause systematic biases that can vary as a function of atmospheric opacity, and add to the natural variance in the profile. The peak in $\mathrm{O}_{3}$ at about $35-40 \mathrm{~km}$ (can be seen in the a priori profile) is, on average, lowest in January and increases through March. The lower altitude peak at about $25 \mathrm{~km}$ decreases in March compared to January and February. This general change in the altitude of the global maximum of $\mathrm{O}_{3}$ can be expected if the polar vortex weakens and breaks up toward the end of winter, but individual years show strong variation in vortex break-up and reformation times related to SSWs and other variations in wave activity.

In the left panel of Fig. 14, for January and February, every year shows an $\mathrm{O}_{3}$ dip to some degree (most pronounced in 2010 and least in 2008), and at varying altitudes. These 

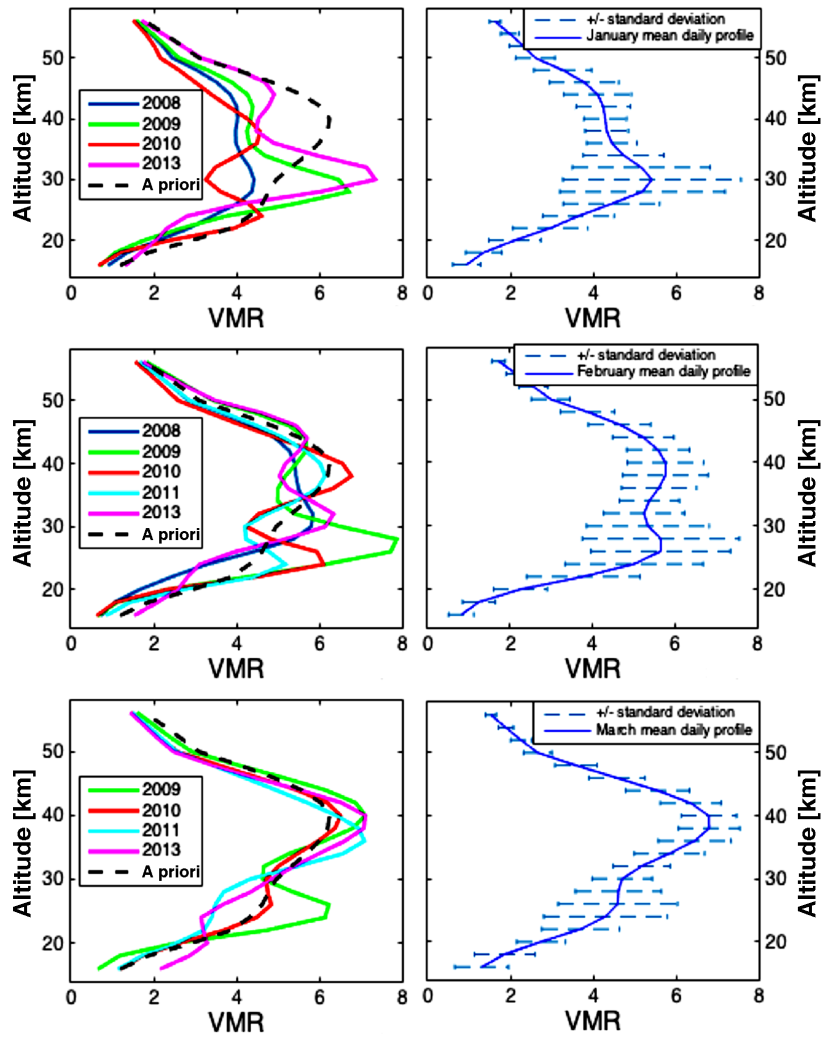

Figure 14. Left: monthly averages of daily Kiruna $\mathrm{O}_{3}$ profiles (in ppmv) from KIMRA measurements for January, February, and March by year. A missing year means that there were not enough measurements during the month to produce a representative average. Right: mean and standard deviation of the daily profiles for each month.

features tend to decrease in magnitude in March, except for 2009, which maintains an $\mathrm{O}_{3}$ dip greater than 1 ppmv. While it is emphasised here that this feature is not purely a result of the described biases in KIMRA $\mathrm{O}_{3}$, it will be difficult to quantitatively separate the two features.

\section{Summary and conclusions}

The aim of this work is to develop and deploy an inversion scheme for the KIMRA and MIRA 2 instruments at IRF, Kiruna, and to characterize the retrieved $\mathrm{O}_{3}$ profiles, through comparison with each other and with $\mathrm{O}_{3}$ profiles from ozonesondes launched from Sodankylä and from Aura MLS. KIMRA and MIRA $2 \mathrm{O}_{3}$ profiles from November 2012 to May 2013 were used in the comparison. The retrieval altitude range for the $\mathrm{O}_{3}$ profiles is approximately $16-54 \mathrm{~km}$, with a resolution of, at best, $8 \mathrm{~km}$, derived from the full width at half maximum (FWHM) of the averaging kernels. KIMRA and MIRA 2 profiles show generally good agreement with each other. The mean of the difference in their profiles (bias) lies within $\sim \pm 1$ ppmv.
An oscillatory bias was identified in the KIMRA data: there is a low bias of $\sim 1$ ppmv at $22 \mathrm{~km}$, and a high bias of $\sim 1 \mathrm{ppmv}$ at $28 \mathrm{~km}$, both with a half width of $\sim 5 \mathrm{~km}$. MIRA 2 shows an oscillatory bias, but with smaller amplitude $(<0.5 \mathrm{ppmv})$ and finer altitude structure, which covers the whole retrieval altitude range. Both KIMRA and MIRA 2 otherwise show generally good agreement with $\mathrm{MLS} \mathrm{O}_{3}$ profiles, and KIMRA shows a general low bias with respect to the ozonesondes. MIRA 2 shows overall better agreement with MLS and the ozonesondes, compared to KIMRA, but both ground-based datasets show some differences that are not explained by random errors. The relatively stable oscillatory structures present in the KIMRA profiles are assumed to be caused by a mixture of baseline waves in the spectra, but their origin is not known. A recent servicing of the MIRA 2 AOS has eliminated the visible oscillation in the MIRA 2 spectra.

KIMRA $\mathrm{O}_{3}$ profiles from January to March, 2008, 2009, 2010, 2011, and 2013 were used to explore the local day-today variability of $\mathrm{O}_{3}$ above Kiruna. The middle stratosphere between approximately 20 and $33 \mathrm{~km}$ shows the most variability. The lowest $\mathrm{O}_{3}$ concentrations are found in January, and tend to increase through March. The location of the maximum in the $\mathrm{O}_{3}$ profile shifts from $\sim 30 \mathrm{~km}$ in January to $\sim 39 \mathrm{~km}$ (the location of the maximum in the a priori profile) in March. The most interesting feature in the data is a local minimum in the $\mathrm{O}_{3}$ profile, present to some extent in all years and can be persistent for timescales larger than 2 months. The feature may be difficult to quantitatively assess with KIMRA because it tends to partially overlap in altitude with the oscillatory bias in the KIMRA data. Previous measurements with KIMRA during winter 2002/2003 showed a similar local minimum in the $\mathrm{O}_{3}$ profile throughout most of December 2002.

\section{Data availability}

The data produced for KIMRA and MIRA 2 are provided as a supplement to this article. The Aura MLS v3.3/3.4 data are available from the Goddard Earth Sciences Data and Information Center at http://disc.gsfc.nasa. gov/datacollection/ML2O3_003.html (EOS MLS Science Team, 2011). The Sodankylä ozonesonde data were provided by Rigel Kivi and are available from the Network for Detection of Atmospheric Composition Change (NDACC) archive at ftp://ftp.cpc.ncep.noaa.gov/ndacc/station/sodanky/ ames/o3sonde/ (NDACC, 2016). sPV values were provided in the derived meteorological products by Gloria Manney and William Daffer at the Jet Propulsion Laboratory, California Institute of Technology. 


\section{The Supplement related to this article is available online at doi:10.5194/amt-9-4503-2016-supplement.}

Acknowledgements. This work was supported by the NSERC CREATE Training Program in Arctic Atmospheric Science, the Centre for Global Change Science of the University of Toronto, the Institute of Space Physics, Kiruna, and the German Federal Ministry of Education and Research ROMIC project. Thank you to William Daffer at Jet Propulsion Laboratory, California Institute of Technology, for help in providing the derived meteorological data used in this work. Thank you to Philip Heron for the geographical plots. We thank the anonymous referees for their helpful comments.

Edited by: D. Ruffieux

Reviewed by: two anonymous referees

\section{References}

Anderson, G. P., Clough, S. A., Kneizys, F. X., Chetwynd, J. H., and Shettle, E. P.: AFGL atmospheric constituent profiles (0$120 \mathrm{~km}$ ), Tech. Rep. TR-86-0110, AFGL, 1986.

Berg, H., Krupa, R., Hochschild, G., Kopp, G., and Kuntz, M.: Millimeter wave radiometer with adjustable internal calibration load for high resolution measurements of stratospheric constituents. Proceedings of 2nd ESA Workshop on Millimetre Wave Technology and Applications: Antennas, Circuits and Systems, May 1998, Espoo, 372-377, 1998.

Deshler, T., Mercer, J., Smit, H., Stubi, R., Levrat, G., Johnson, B., Oltmans, S., Kivi, R., Thompson, A., Witte, J., Davies, J., Schmidlin, F., Brothers, G., and Sasaki, T.: Atmospheric comparison of electrochemical cell ozonesondes from different manufacturers, and with different cathode solution strengths: The Balloon Experiment on Standards for Ozonesondes. J. Geophys. Res., 113, D04307, doi:10.1029/2007JD008975, 2008.

Dirksen, R. J., Sommer, M., Immler, F. J., Hurst, D. F., Kivi, R., and Vömel, H.: Reference quality upper-air measurements: GRUAN data processing for the Vaisala RS92 radiosonde, Atmos. Meas. Tech., 7, 4463-4490, doi:10.5194/amt-7-4463-2014, 2014.

EOS MLS Science Team: MLS/Aura Level 2 Ozone (O3) Mixing Ratio V003, version 003 from Goddard Earth Sciences Data and Information Services Center (GES DISC), Greenbelt, MD, USA, available at: http://disc.gsfc.nasa.gov/datacollection/ ML2O3_003.html (last access: February 2003), 2011.

Eriksson, P., Jimenez, C., and Buehler, S. A.: Qpack, a general tool for instrument simulation and retrieval work, J. Quant. Spectrosc. Ra., 91, 47-64, 2005.

Eriksson, P., Buehler, S. A., Davis, C. P., Emde, C., and Lemke, O.: ARTS, the atmospheric radiative transfer simulator, Version 2, J. Quant. Spectrosc. Ra., 112, 1551-1558, 2011.

Froidevaux, L., Jiang, Y. B., Lambert, A., Livesey, N. J., Read, W. G., Waters, J. W., Browell, E. V., Hair, J. W., Avery, M. A., McGee, T. J., Twigg, L.W., Sumnicht, G. K., Jucks, K.W., Margitan, J. J., Sen, B., Stachnik, R. A., Toon, G. C., Bernath, P.F., Boone, C. D., Walker, K. A., Filipiak, M. J., Harwood, R. S., Fuller, R. A., Manney, G. L., Schwartz, M. J., Daffer, W. H., Drouin, B. J., Cofield, R. E., Cuddy, D. T., Jarnot, R. F.,
Knosp, B. W., Perun, V. S., Snyder, W. V., Stek, P. C., Thurstans, R. P., and Wagner, P. A.: Validation of Aura Microwave Limb Sounder stratospheric ozone measurements, J. Geophys. Res., 113, D15S20, doi:10.1029/2007JD008771, 2008.

Golchert, S. H. W, Buschmann, N., Kleindienst, A., Palm, M., Schneider, N., Jønch-Sørensen H., and Notholt, J.: Starting longterm stratospheric observations with RAMAS at Summit, Greenland, IEEE T. Geosci. Remote., 43, 1022-1027, 2005.

Harvey, L. V., Pierce, B. R., Fairlie, D. T., and Hitchman, M. H.: A climatology of stratospheric polar vortices and anticyclones. J. Geophys. Res., 107, 4442, doi:10.1029/2001JD001471, 2002.

Hassler, B., Petropavlovskikh, I., Staehelin, J., August, T., Bhartia, P. K., Clerbaux, C., Degenstein, D., De Mazière, M., Dinelli, B. M., Dudhia, A., Dufour, G., Frith, S. M., Froidevaux, L., GodinBeekmann, S., Granville, J., Harris, N. R. P., Hoppel, K., Hubert, D., Kasai, Y., Kurylo, M. J., Kyrölä, E., Lambert, J.-C., Levelt, P. F., McElroy, C. T., McPeters, R. D., Munro, R., Nakajima, H., Parrish, A., Raspollini, P., Remsberg, E. E., Rosenlof, K. H., Rozanov, A., Sano, T., Sasano, Y., Shiotani, M., Smit, H. G. J., Stiller, G., Tamminen, J., Tarasick, D. W., Urban, J., van der A, R. J., Veefkind, J. P., Vigouroux, C., von Clarmann, T., von Savigny, C., Walker, K. A., Weber, M., Wild, J., and Zawodny, J. M.: Past changes in the vertical distribution of ozone - Part 1: Measurement techniques, uncertainties and availability, Atmos. Meas. Tech., 7, 1395-1427, doi:10.5194/amt-7-1395-2014, 2014.

Hoffmann, C. G., Raffalski, U., Palm, M., Funke, B., Golchert, S. H. W., Hochschild, G., and Notholt, J.: Observation of stratomesospheric CO above Kiruna with ground-based microwave radiometry - retrieval and satellite comparison, Atmos. Meas. Tech., 4, 2389-2408, doi:10.5194/amt-4-2389-2011, 2011.

IPCC 2013: Climate Change 2013: Working group contribution to the Fifth Assessment Report of the Intergovernmental Panel on Climate Change, 2013.

Jiang, Y. B., Froidevaux, L., Lambert, A., Livesey, N. J., Read, W. G., Waters, J. W., Bojkov, B., Leblanc, T., McDermid, I. S., Godin-Beekmann, S., Filipiak, M. J., Harwood, R. S., Fuller, R. A., Daffer, W. H., Drouin, B. J., Cofield, R. E., Cuddy, D. T., Jarnot, R. F., Knosp, B. W., Perun, V. S., Schwartz, M. J., Snyder, W. V., Stek, P. C., Thurstans, R. P., Wagner, P. A., Allaart, M., Andersen, S. B., Bodeker, G., Calpini, B., Claude, H., Coetzee, G., Davies, J., De Backer, H., Dier, H., Fujiwara, M., Johnson, B., Kelder, H., Leme, N. P., Konig-Lanlo, G., Kyro, E., Laneve, G., Fook, L. S., Merrill, J., Morris, G., Newchurch, M., Oltmans, S., Parrondos, M. C., Posny, F., Schmidlin, F., Skrivankova, P., Stubi, R., Tarasick, D., Thompson, A., Thouret, V., Viatte, P., Vomel, H., von der Gathen, P., Yela, M., and Zablocki, G.: Validation of Aura Microwave Limb Sounder Ozone by ozonesonde and lidar measurements, J. Geophys. Res., 112, D24S34, doi:10.1029/2007JD008776, 2007.

Jin, J. J., Semeniuk, K., Manney, G. L., Jonsson, A. I., Beagley, S. R., McConnell, J. C., Dufour, G., Nassar, R., Boone, C. D., Walker, K. A., Bernath, P. F., and Rinsland, C. P.: Severe Arctic ozone loss in the winter 2004/2005: observations from ACE-FTS, Geophys. Res. Lett., 33, L15801, doi:doi:10.1029/2006GL026752, 2006.

Kivi, R., Kyrö, E., Turunen, T., Harris, N. R. P., von der Gathen, P., Rex, M., Anderson, S. B., and Wohltmann, I.: Ozonesonde observations in the Arctic during 1989-2003: Ozone variability 
and trends in the lower stratosphere and free troposphere, J. Geophys. Res., 112, D08306, doi:doi:10.1029/2006JD007271, 2007.

Kopp, G.: Inversion arktischer stratosphärischer Spurengasprofile für die Ozonforschung aus Messungen eines bodengebundenen Millimeterwellenradiometers, Wiss. Ber., FZK Rep. 6563, Forsch. Karlsruhe, Karlsruhe, Germany, 2000.

Kopp, G., Berg, H., Blumenstock, T., Fischer, H., Hase, F., Hochschild, G., Hoepfner, M., Kouker, W., Reddmann, T., Ruhnke, R., Raffalski, U., and Kondo Y.: Evolution of ozone and ozone-related species over Kiruna during the SOLVE/THESEO 2000 campaign retrieved from ground-based millimeter-wave and infrared observations, J. Geophys. Res., 107, 51(1)-51(12), doi:10.1029/2001JD001064, 2003.

Kopp, G., Belova. A., Diez y Riega V., E., Gross, J., Hochschild, G., Hoffmann, P., Murtagh, D., Raffalksi, U., and Urban, J.: Intercomparison of Odin-SMR ozone profiles with ground-based observations in the Arctic, the mid-latitudes, and the tropics, Can. J. Phys., 85, 1097-1110, 2007.

Kuttippurath, J. and Nikulin, G.: A comparative study of the major sudden stratospheric warmings in the Arctic winters 2003/2004-2009/2010, Atmos. Chem. Phys., 12, 8115-8129, doi:10.5194/acp-12-8115-2012, 2012.

Kuttippurath, J., Godin-Beekmann, S., Lefèvre, F., and Goutail, F.: Spatial, temporal, and vertical variability of polar stratospheric ozone loss in the Arctic winters 2004/2005-2009/2010, Atmos. Chem. Phys., 10, 9915-9930, doi:10.5194/acp-10-9915-2010, 2010.

Langer, J., Barry, B., Klein, U., Sinnhuber, B.-M., Wohltmann, I., and Kuenzi, K. F.: Chemical ozone depletion during Arctic winter 1997/98 derived from ground based millimeter-wave observations, Geophys. Res. Lett., 26, 599-602, 1999.

Liebe, H. J., Hufford G. A., and Cotton, M. G.: Propagation modeling of moist air and suspended water/ice particles at frequencies below $1000 \mathrm{GHz}$. AGARD 52nd Specialists' Meeting of the Electromagnetic Wave Propagation Panel, 17-21 May 1993, Palma De Mallorca, Spain, 1993.

Livesey, N. J., Filipiak, M. J., Froidevaux, L., Read, W. G., Lambert, A., Santee, M. L., Jiang, J. H., Waters, J. W., Cofield, R. E., Cuddy, D. T., Daffer, W. H., Drouin, B. J., Fuller, R. A., Jarnot, R. F., Jiang, Y. B., Knosp, B. W., Li, Q. B., Perun, V. S., Schwartz, M. J., Snyder, W. V., Stek, P. C., Thurstans, R. P., Wagner, P. A., Pumphrey, H. C., Avery, M., Browell, E. V., Cammas, J.-P., Christensen, L. E., Edwards, D. P., Emmons, L. K., Gao, R.-S., Jost, H.-J., Loewenstein, M., Lopez, J. D., Nédélec, P., Osterman, G. B., Sachse, G. W., and Webster, C. R.: Validation of Aura Microwave Limb Sounder $\mathrm{O}_{3}$ and $\mathrm{CO}$ observations in the upper troposphere and lower stratosphere, J. Geophys. Res., 113, D15S02, doi:10.1029/2007JD008805, 2008.

Livesey, N. J., Read W. G., Froidevaux, L., Lambert, A., Manney, G. L., Pumphrey, H. C., Santee, M. L., Schwartz, M. J., Wang, S., Coeld, R. E., Cuddy, D. T., Fuller, R. A., Jarnot, R. F., Jiang, H. J., Knosp, B. W., Stek, P. C., Wagner, P. A., and Wu, D. L.: Version 3.3 and 3.4 Level 2 data quality and description document, Tech. Rep. JPL D-33509, Jet Propulsion Laboratory, Pasadena, CA, USA, available at: http://mls.jpl.nasa.gov/data/v3_data_quality_ document.pdf (last access: January 2014), 2013.

Livesey, N. J., Santee, M. L., and Manney, G. L.: A Match-based approach to the estimation of polar stratospheric ozone loss us- ing Aura Microwave Limb Sounder observations, Atmos. Chem Phys., 15, 9945-9963, doi:10.5194/acp-15-9945-2015, 2015.

Manney, G. L., Zurek, R. W., O’Neill, A., Swinbank, R., Kumer, J. B., Mergenthaer, J. L., and Roche A. E.: Stratospheric warmings during February and March 1993, Geophys. Res. Lett., 21, 813816, 1994a.

Manney, G. L., Zurek, R.W., O’Neill, A., and Swinbank, R.: On the motion of air through the stratospheric polar vortex, J. Atmos. Sci., 51, 2973-2994, 1994b.

Manney, G. L., Froidevaux L., Waters J. W., and Zureck R. W.: Evolution of microwave limb sounder ozone and the polar vortex during winter, J. Geophys. Res., 100, 2953-2972, 1995.

Manney, G. L., Froidevaux, L., Santee, M. L., Livesey, N. J., Sabutis, J. L., and Waters, J. W.: Variability of ozone loss during Arctic winter (1991 to 2000) estimated from UARS Microwave Limb Sounder measurements, J. Geophys. Res., 108, 4149, doi:10.1029/2002JD002634, 2003.

Manney, G. L., Daffer, W. H., Zawodny, J. M., Bernath, P. F., Hoppel, K. W., Walker, K. A., Knosp, B. W., Boone, C., Remsberg, E. E., Santee, M. L., Harvey, V. L., Pawson, S., Jackson, D. R., Deaver, L., McElroy, C. T., McLinden, C. A., Drummond, J. R., Pumphrey, H. C., Lambert, A., Schwartz, M. J., Froidevaux, L., McLeod, S., Takacs, L. L., Suarez, M. J., Trepte, C. R., Cuddy, D. C., Livesey, N. J., Harwood, R. S., and Waters, J. W.: Solar occultation satellite data and derived meteorological products: sampling issues and comparisons with Aura Microwave Limb Sounder, J. Geophys. Res., 112, D24S50, doi:10.1029/2007JD008709, 2007.

Manney, G. L., Santee, M. L., Rex, M., Livesey, N. J., Pitts, M. C., Veefkind, P., Nash, E. R., Wohltmann, I., Lehmann, R., Froidevaux, L., Poole, L. R., Schoeberl, M. R., Haffner, D. P., Davies, J., Dorokhov, V., Gernandt, H., Johnson, B., Kivi, R., Kyro, E., Larsen, N., Levelt, P. F., Makshtas, A., McElroy, C. T., Nakajima, H., Parrondo, M. C., Tarasick, D. W., von der Gathen, P., Walker K. A., and Zinoviev, N. S.: Unprecedented Arctic Ozone loss in 2011, Nature, 478, 469-475, doi:10.1038/nature10556, 2011.

Manney, G. L., Lawrence, Z. D., Santee, M. L., Livesey, N. J., Lambert, A., and Pitts, M. C.: Polar processing in a split vortex: Arctic ozone loss in early winter 2012/2013, Atmos. Chem. Phys., 15, 5381-5403, doi:10.5194/acp-15-5381-2015, 2015.

Marquardt, D.: An Algorithm for Least Squares Estimation on Nonlinear Parameters, J. Soc. Ind. Appl. Math., 11, 431-441, 1963.

Meijer, Y. J., Swart, D. P. J., Allaart, M., Andersen, S. B, Bodeker, G., Boyd, I., Braathen, G., Calisesi, Y., Claude, H., Dorokhov, V., von der Gathen, P., Gil, M., Godin-Beekmann, S., Goutail, F., Hansen, G., Karpetchko, A., Keckhut, P., Kelder, H. M., Koelemeijer, R., Kois, B., Koopman, R. M., Kopp, G., Lambert, J.C., Leblanc, T., McDermid, I. S., Pal, S., Schets, H., Stubi, R., Suortti, T., Visconti, G., and Yela, M.: Pole-to-pole validation of Envisat GOMOS ozone profiles using data from ground-based and balloon sonde measurements, J. Geophys. Res., 109, 115126, 2004.

NDACC: The Sodankylä ozonesonde data in the NDACC database, available at: ftp://ftp.cpc.ncep.noaa.gov/ndacc/station/sodanky/ ames/o3sonde/, last access: September 2016.

Nedoluha, G. E., Bevilacqua, R. M., Gomez, R. M., Waltman, W. B., Hicks, B. C., Thacker, D. L., Russell III, J. M., Abrams, M., Pumphrey, H. C., and Connor, B. J. A comparative study of mesospheric water vapor measurements from the ground-based 
water vapor millimeter-wave spectrometer and space-based instruments. J. Geophys. Res. 102, 16647-16661, 1997.

Palm, M., v. Savigny, C., Warneke, T., Velazco, V., Notholt, J., Künzi, K., Burrows, J., and Schrems, O.: Intercomparison of $\mathrm{O}_{3}$ profiles observed by SCIAMACHY and ground based microwave instruments, Atmos. Chem. Phys., 5, 2091-2098, doi:10.5194/acp-5-2091-2005, 2005.

Palm, M., Hoffmann, C. G., Golchert, S. H. W., and Notholt, J.: The ground-based MW radiometer OZORAM on Spitsbergen - description and status of stratospheric and mesospheric $\mathrm{O}_{3}$-measurements, Atmos. Meas. Tech., 3, 1533-1545, doi:10.5194/amt-3-1533-2010, 2010.

Raffalski, U., Berg, H., Hochschild, G., and Kopp, G.: Continuous ozone measurements over Kiruna during winter/spring 2002: A new millimeter wave radiometer operated at the Swedish Institute of Space Physics, Kiruna, Sweden, Proceedings of the Sixth European Symposium on Stratospheric Ozone Research, Gothenberg, Sweden, 369-372, 2002.

Raffalski, U., Hochschild, G., Kopp, G., and Urban, J.: Evolution of stratospheric ozone during winter 2002/2003 as observed by a ground-based millimetre wave radiometer at Kiruna, Sweden, Atmos. Chem. Phys., 5, 1399-1407, doi:10.5194/acp-5-13992005, 2005.

Rodgers, C. D.: Characterization and error analysis of profiles retrieved from remote sounding measurements, J. Geophys. Res., 95, 5587-5595, 1990.

Rodgers, C. D: Inverse methods for atmospheric remote sounding: Theory and practice, Vol. 2, Series on atmospheric and ocean physics, World Scientific, Singapore, 2000.

Rodgers, C. D. and Connor, B. J.: Intercomparison of remote sounding instruments, J. Geophys. Res., 108, 4116, doi:10.1029/2002JD002299, 2003.

Rothman, L. S., Gordon, I. E., Barbe, A., Chris Benner, D., Bernath, P. F., Birk, M., Boudon, V., Brown, L. R., Campargue, A., Champion, J.-P., Chance, K., Couderti, L. H., Dana, V., Devi, V. M., Fally, S., Flaud, J.-M., Gamache, R. R., Goldman, A., Jacquemart, D., Kleiner, I., Lacome, N., Lafferty, W. J., Mandin, J.-Y., Massie, S. T., Mikhailenko, S. N., Miller, C. E., Moazzen-Ahmadi, N., Naumenko, O. V., Nikitin, A. V., Orphal, J., Perevalov, V. I., Perrin, A., Predoi-Cross, A., Rinsland, C. P., Rotger, M., Simeckova, M., Smith M. A. H., Sung K., Tashkun, S. A., Tennyson, J., Toth, R. A., Vandaele, A. C., and Vander Auwera, J.: The HITRAN 2008 molecular spectroscopic database, J. Quant. Spectrosc. Ra., 110, 533-572, 2009.

Schoeberl, M. R., Lait, L. R., Newman, P. A., and Rosenfield, J. E.: The structure of the polar vortex, J. Geophys. Res., 97, 7859$7882,1992$.
Smit, H. G. J. and the Panel for the Assessment of Standard Operation Procedures for Ozonesondes (ASOPOS): Quality Assurance and Quality Control for Ozonesonde Measurements in GAW, available at: http://www.wmo.int/pages/ prog/arep/gaw/documents/GAW_201_30_Sept.pdf (last access: February 2016), 2011.

Steck, T., von Clarmann, T., Fischer, H., Funke, B., Glatthor, N., Grabowski, U., Höpfner, M., Kellmann, S., Kiefer, M., Linden, A., Milz, M., Stiller, G. P., Wang, D. Y., Allaart, M., Blumenstock, Th., von der Gathen, P., Hansen, G., Hase, F., Hochschild, G., Kopp, G., Kyrö, E., Oelhaf, H., Raffalski, U., Redondas Marrero, A., Remsberg, E., Russell III, J., Stebel, K., Steinbrecht, W., Wetzel, G., Yela, M., and Zhang, G.: Bias determination and precision validation of ozone profiles from MIPAS-Envisat retrieved with the IMK-IAA processor, Atmos. Chem. Phys., 7, 3639-3662, doi:10.5194/acp-7-3639-2007, 2007.

Straub, C., Murk, A., and Kämpfer, N.: MIAWARA-C, a new ground based water vapour radiometer for measurement campaigns, Atmos. Meas. Tech., 3, 1271-1285, doi:10.5194/amt-31271-2010, 2010.

UNEP: Synthesis of the 2014 Reports of the Scientific, Environmental Effects, and Technology \& Economic Assessment Panels of the Montreal Protocol, United Nations Environment Programme (UNEP), Nairobi, 2015.

Waters, J. W., Froidevaux, L., Harwood, R., Jarnot, R., Pickett, H., Read, W., Siegel, P., Cofield, R., Filipiak, M., Flower, D., Holden, J., Lau, G., Livesey, N., Manney, G., Pumphrey, H., Santee, M., Wu, D., Cuddy, D., Lay, R., Loo, M., Perun, V., Schwartz, M., Stek, P., Thurstans, R., Boyles, M., Chandra, S., Chavez, M., Chen, G.-S., Chudasama, B., Dodge, R., Fuller, R., Girard, M., Jiang, J., Jiang, Y., Knosp, B., LaBelle, R., Lam, J., Lee, K., Miller, D., Oswald, J., Patel, N., Pukala, D., Quintero, O., Scaff, D., Snyder, W., Tope, M., Wagner, P., and Walch, M.: The Earth Observing System Microwave Limb Sounder (EOS MLS) on the Aura satellite, IEEE T. Geosci. Remote, 44, 11061121, 2006.

WMO (World Meteorological Organization): Scientific assessment of ozone depletion: 2014, Global Ozone Research and Monitoring Project-Report No. 55, Geneva, Switzerland, 2014.

York, D., Evensen, N. M., Martinez, M. L., and Delgado J. D. B.: Unified equations for the slope, intercept, and standard errors of the best straight line, Am. J. Phys., 72, 367-375, 2004. 